\title{
That's Not Fair: Tariff Structures for Electric Utilities with Rooftop Solar
}

\author{
Siddharth Prakash Singh \\ UCL School of Management; siddharth.singh@ucl.ac.uk \\ Alan Scheller-Wolf \\ Tepper School of Business, Carnegie Mellon University; awolf@andrew.cmu.edu
}

(1) Problem definition: Utility regulators are grappling to devise compensation schemes for customers who sell rooftop solar generation back to the grid, balancing environmental interests and the financial interests of utilities, solar system installers, and retail customers. This is difficult: Regulatory changes made in Nevada in 2015 to protect Nevada's utility induced SolarCity, the market leader in solar systems, to suspend local operations. We show that the choice of tariff structure is crucial to achieving socially desirable objectives.

(2) Academic/Practical Relevance: It is important for regulators to understand how tariff structure interacts with social objectives. This has implications for consumers, regulators and industry.

(3) Methodology: We use a sequential game to analyze the regulator's social welfare maximization problem in a market with a regulated utility, an unregulated, price-setting, profit-maximizing solar system installer, and customers who endogenously determine whether to adopt solar or not, based on utility tariffs, solar prices and their heterogeneous usage profiles and generation potentials.

(4) Results: We illustrate that the effectiveness of tariff structures is not governed simply by the number of free tariff parameters, but by the functions these parameters serve. In particular, an effective tariff must discriminate among customer usage tiers and between customers with and without rooftop solar to achieve socially desirable outcomes. We present a tariff structure with these two characteristics and show how it can be implemented as a simple buy-all, sell-all tariff while retaining its favorable properties. We illustrate our findings numerically using data from Nevada and New Mexico, two states grappling with this issue.

(5) Managerial Implications: Many utilities in the U.S. operate tariff structures that are missing at least one of the two identified features. Regulators must overhaul these tariff structures to adequately safeguard all stake-holders.

Key words: rooftop solar, net-metering, energy policy, game theory

\section{Introduction}

Rooftop solar has seen a boom in recent years, with residential rooftop solar installations consistently growing at over 20\% year-on-year (Mike Munsell, 2017). One of the main catalysts for this growth has been the practice of utility companies offering "retail net-metering" to customers with 
solar panels: Under this scheme, these customers can sell any excess electricity they generate to their utility for full retail credit. Effectively, such customers pay only for their "net" usage.

While this incentive is useful because a move to rooftop solar is environmentally desirable, retail net-metering threatens the profitability of utility companies, who are forced to buy excess energy from customers at retail rates which are significantly higher than their prevailing procurement costs. A utility might commonly combat this by raising retail electricity rates for all users, or by reducing the rate at which utilities repurchase excess generation from solar households. However, both these solutions are problematic: If the utility company raises rates, (typically) poorer non-solar households would bear some part of the burden imposed by (typically) wealthier solar households (Krysti Shallenberger, 2017a), resulting in cross-subsidization, a phenomenon under which one set of customers benefits at the cost of another set of customers. Alternately, if the repurchase rate is reduced, customers may no longer be install solar, and solar installers could be put out of business. Below we discuss how this latter dynamic played out recently in Nevada (Buhayar, 2016).

In each of the thirty-three U.S. states with regulated electricity markets (Electricity Local, 2019), a body called the Public Utilities Commission (PUC) has the charge of solving this complex problem: The PUC balances the welfare of the various stake-holders by regulating the rates and services of public utilities. The PUCs can therefore be thought of as social welfare maximizers; in the context of rooftop solar, this means protecting utility company profitability and ensuring fair rates for customers, while also providing a nourishing environment for rooftop solar in order to protect environmental interests. (PUCs' stated objectives often explicitly include environmental stewardship; see California Public Utilities Commission (2020).) The PUC's task is further complicated by the fact that solar system installers (henceforth solar companies) are typically unregulated; therefore, regulatory interventions must account for such solar companies making self-interested decisions.

As might be expected, increased rooftop solar adoption and its effects on utility companies' profits has resulted in considerable regulatory flux: In the U.S. 42 of the 50 states took some action related to net-metering, rate design or solar ownership during the third quarter of 2019 alone (NC Clean Energy Technology Center and Meister Consultants Group, 2019). The PUC's regulatory tight-rope walk of balancing customer, societal and utility welfare is a tricky affair that has, on occasion, gone awry. NV Energy, the utility in Nevada, imposes a simple two-part tariff: a monthly fixed charge and a variable "energy" charge per kWh of energy consumed. After being negatively impacted by increased rooftop solar adoption, NV Energy initiated a prolonged dialogue with their PUC, in which they explicitly raised the specter of cross-subsidization (Chediak and Buhayar, 2015). The outcome of this dialogue was a ruling that solar customers would eventually pay thrice 
as high a fixed charge as non-solar customers, and would be credited for excess generation at procurement cost (significantly lower than the existing retail rate). This announcement prompted SolarCity, the market leader in solar systems, to suspend operations in Nevada and cut over 500 jobs (Buhayar, 2016). In December 2016, a year after this ruling was made, the PUC reversed itself, voting to restore retail net-metering and the original rate schedule in the Sierra Pacific territory (Pyper, 2016). Meanwhile, in February 2017 in Maine, the PUC passed a bill to phase down compensation paid to customers for their excess generation. In July 2017, a new bill that aimed to roll back this decision in order to boost solar growth was vetoed by the Governor, who cited cross-subsidization as the reason for his decision: He said that net-metering subsidizes the cost of solar panels "at the expense of the elderly and poor who can least afford it" (Krysti Shallenberger, 2017b). In April 2019, Maine voted to restore net-metering (State of Maine, 2019).

Despite the apparent pressing need, there is no evident consensus on the structural properties a tariff should have in order to be effective in a solar market. For instance, NV Energy (Nevada) and Duke Energy (North Carolina) have only a single tier in their tariff structures, i.e., all customers are charged the same variable rate and the same fixed cost regardless of how much they consume, whereas PNM Energy (New Mexico) and Idaho Power (Idaho) have three tiers. Tariffs also vary in whether they discriminate between solar and non-solar customers: Nevada permits NV Energy to have solar and non-solar customers on different rate schedules, but states such as New Mexico and Washington explicitly disallow this. Meanwhile, Arizona Public Service (APS) has a tiered tariff structure that pays solar customers less than the retail rate for excess energy sold back, effectively putting them on different rate schedules from non-solar customers.

Motivated by this current regulatory flux, we explore the delicate problem faced by the PUCs, focusing on how effective different tariff structures are in enabling the PUC to induce socially optimal welfare outcomes in the presence of residential rooftop solar. We do so by explicitly modeling the regulator's social welfare optimization problem, and demonstrate that some common tariff forms are potentially inadequate to the task. We consider a monopolistic, vertically integrated utility company (like NV Energy-such utilities operate in regulated electricity markets where customers cannot freely choose a retail utility to supply them) whose tariffs are set by the PUC; a monopolistic, price-setting solar company (similar to SolarCity); and residential customers who are heterogeneous in their demands and generation capability (available roof space) ${ }^{1}$. First, the PUC fixes a tariff (possibly upon negotiation with the utility company). The PUC's choice of tariff then influences the solar company's pricing decision, (and hence its profitability), which in turn

\footnotetext{
${ }^{1}$ We ignore commercial customers for tractability.
} 
influences customers' adoption decisions. (In Nevada, the tariff choice caused SolarCity to exit the state because they anticipated not being able to set a price that would keep them profitable.) We model the response of the solar company and the customers using a sequential game: The solar company responds to the tariff by setting a price of solar systems to maximize its profit, anticipating customers' endogenous decisions to install solar or not. Customers make their self-interested installation decision based on the tariff set by the PUC, the solar company's chosen price, and their demand, rooftop solar generation potential, and excess generation that they expect to sell back to the grid (together, these determine a customer's usage "tier" or "profile").

The solar company's endogenous pricing decision creates incentive compatibility and participation constraints that the regulator must account for, failing which the solar company may exit the market (as they did in Nevada). Our base model considers a monopolistic solar marketplace: In the U.S. SolarCity (now Tesla) was the market leader with a 34\% market share in 2014 and 2015 (Meyers, 2015), and lower costs (Shahan, 2016), thereby giving it price-setting power. In fact, although SolarCity's market share has since dropped, its price is still $16 \%$ lower than the market average (Reisinger, 2019). We extend our model to an oligopoly with Cournot competition and endogenously determined price.

We find that a tariff structure's effectiveness is driven not just by the number of free parameters, but by the specific function that they serve. In particular, we find that a tariff structure must have two attributes in order to guarantee effectiveness: the ability to discriminate between customers based on their usage tier, and the ability to discriminate between customers with and without rooftop solar. While APS's tariff structure has both these features, at least one of them is absent in the tariff structures of many other utilities, for example, NV Energy and PNM Energy. In the absence of either one of these attributes, the regulator might not be able to induce a socially optimal outcome, often yielding an outcome that includes cross-subsidization. We then show that a simple two-part tariff with these two attributes, featuring full retail price repurchasing from residential solar customers, always guarantees feasibility of the regulator's social welfare optimization problem. If solar adoption generates an overall customer surplus (possibly at the expense of the utility), this tariff structure also guarantees an outcome with no cross-subsidization. We then suggest a buy-all, sell-all tariff such as the one proposed in Indiana (Kari Lyderson, 2017) as a simple implementation of our suggested tariff, and show that this tariff retains desirable properties.

Complementary to our analysis, using household consumer survey data (U.S. Energy Information Administration, 2009), we estimate customer usage profile parameters and numerically illustrate how our suggested tariff structure compares to the tariff structures currently in use in Nevada and New Mexico, two states wrestling with this issue. We find that both states' tariffs perform poorly compared to our suggested tariff: while our tariff is able to avoid cross-subsidization in all test cases, the current tariffs in both states cannot. 
Singh, Scheller-Wolf: That's Not Fair: Tariff Structures for Electric Utilities with Rooftop Solar

\section{Literature Review}

There is a substantial body of Operations Management literature exploring various aspects related to managing renewable energy resources. Aflaki and Netessine (2016) and $\mathrm{Hu}$ et al. (2015) study capacity investment decisions for renewable resources such as wind and solar. The effect of tariff structures on such investments has been studied in Alizamir et al. (2016), Ritzenhofen et al. (2016), and Kok et al. (2015). The operational aspects of managing such resources are studied in Zhou et al. (2014), Wu and Kapuscinski (2013), Sunar and Birge (2018) and Al-Gwaiz et al. (2016). We contribute to this literature by analyzing the structural requirements for a utility tariff to induce welfare optimal and fair outcomes for the utility, the solar industry, and customers.

The energy policy literature contains a stream of work investigating regulatory considerations arising from the increase in distributed generation. Some of these papers, such as Keyes and Rábago (2013) and Lehr (2013) provide frameworks for regulation. Linvill et al. (2013) qualitatively discuss the challenges a regulator might face when implementing net-metering or feed-in tariffs for compensating distributed generation. Some studies such as Blackburn et al. (2014), Borlick and Wood (2014), Brown and Bunyan (2014) and Moore et al. (2016) find that current subsidy levels in tandem with net-metering tend to overcompensate customers for excess generation. Aznar and Zinaman (2017), Flores-Espino (2015) and Lowder et al. (2017) provide a detailed discussion of various tariff options for managing distributed solar generation. NC Clean Energy Technology Center and Meister Consultants Group (2019) provides a comprehensive view of recent solar-related regulatory changes that have been made in the 50 states in the U.S. We contribute to this policy discussion by formulating and solving an analytical model to study various compensation schemes.

Bird et al. (2013) describe the role of the regulator in a changing electricity landscape as: (1) keeping the utility company viable, resulting in relatively stable cash flows and revenues from year to year; (2) fairly apportioning the utility's cost of service among customers, without undue discrimination; and (3) promotion of economic efficiency in the use of energy as well as competing products and services, without compromising on reliability. We formulate and solve an analytical model to explore which tariff structures enable the regulator to induce market outcomes in keeping with these criteria.

Another stream of literature studies the diffusion of solar among customers. Simulation approaches are common (Denholm et al., 2009), and are used as a building block for research such as Gagnon and Sigrin (2015) and Drury et al. (2013). There is also a large body of empirical literature in this stream; see Ong et al. (2010), Lobel and Perakis (2011), Bauner and Crago (2015), Darghouth et al. (2011), Cai et al. (2013), Bollinger and Gillingham (2012), Rai and Sigrin (2013), 
and Agarwal et al. (2015) for examples. One possible response to solar adoption eroding their profits is for utilities to raise electricity rates, making solar energy even more attractive, further undermining utility profitability. This so-called "death spiral" behavior is studied in Satchwell et al. (2015), Costello and Hemphill (2014), Denholm et al. (2009) and Darghouth et al. (2016).

Sunar and Swaminathan (2018) study the impact of net metering policies on utility profits by quantifying the impact of net-metered distributed generation on the wholesale market, and hence on utility profit. In contrast to our approach, they treat the adoption level of distributed generation as exogenous and customers as identical. On the other hand, we do not model the wholesale market and the effect of distributed generation on it.

Closer to our work, Babich et al. (2020) model a government entity deciding between offering a feed-in-tariff and a tax-rebate policy for rooftop solar. They study how the chosen policy affects the solar panel investment decisions of a representative household in the presence of exogenous shocks that affect generation efficiency, variability in electricity price and solar panel investment cost (i.e., they have a dynamic model, but with exogenously given solar prices). Our work also deals with aspects of renewable energy that involve decisions by a principal (the PUC) and customers; however, our paper presents a static (rather than dynamic) model of solar adoption among heterogeneous customers who make potentially heterogeneous investment decisions, with a solar company that makes an endogenous pricing decision. Our model's static setting allows us to study the question of what the regulator's welfare-optimal choice of tariff should be, and our heterogeneous customer model allows us to study the customer equity implications of solar adoption. In a similar static setting, Agrawal et al. (2019) study the effect of government generation and investment subsidies on a monopolistic solar company's optimal business model decisions, i.e., whether the solar company should offer outright sales, a Power Purchase Agreement (PPA) model and/or a leasing model. As with Babich et al. (2020), this work considers a setting with a homogeneous customer base; they focus on the solar company rather than customer equity.

Similar to our work, Brown et al. (2017) also present a static model of adoption. They take the perspective of a regulator who seeks to induce a welfare-optimal level of solar adoption by setting tariff parameters under a specific tariff function that chooses a payment for distributed generation, a retail rate, and a fixed price for customers. They consider an exogenously defined set of (homogeneous) solar customers and a set of (homogeneous) non-solar customers. In a setting where solar customers install panels to an endogenously determined level to maximize their utility, they demonstrate that the retail net-metering scheme is typically not optimal. Unlike our model, they study only one type of tariff, they treat the price of solar as being exogenously determined 
Singh, Scheller-Wolf: That's Not Fair: Tariff Structures for Electric Utilities with Rooftop Solar

and all their customers as identical, rendering them unable to examine customer equity. Indeed, Brown et al. suggest customer heterogeneity in generation as a potential research direction.

Goodarzi et al. (2019) take the perspective of a regulator who seeks to minimize utility costs by choosing an appropriate feed-in-tariff (FIT) rate paid to customers who sell all their generation to the utility at the FIT rate. In their model, customers are homogeneous in their demand characteristics but heterogeneous in their discount rates, and make a solar adoption decision based on the FIT rate. Similar to our model, their solar system price is chosen endogenously by a profit maximizing solar company. However, in contrast to their paper, we model customers who are heterogeneous in their demands and generation capabilities, and who sell only excess generation back to the grid, enabling us to study customer equity implications. Further, our regulator chooses the tariff structure and parameters, generalizing the FIT rate that Goodarzi et al.'s analysis is restricted to.

Our work also relates to the extensive literature on uniform versus non-linear pricing: We study what features a tariff structure must have in order for a regulator to be able to induce a socially optimal outcome. Varian (1989) and the references therein provide a comprehensive discussion on various issues related to price discrimination: Tiered tariffs are a tool for second-degree price discrimination. While other papers such as Sundararajan (2004) and Choudhary et al. (2005) discuss non-linear pricing for certain specific situations, their findings are not directly applicable to our setting because of our model's unique characteristics: The tariff chosen by the regulator interacts with customers' strategic behavior through the price of solar (which customers use to decide whether to adopt solar or not). This tariff must be chosen so as to induce the solar company to set a price of solar that will induce a socially optimal outcome.

\section{Model}

Our base model considers residential customers who are heterogeneous in their usage profiles, a monopolistic solar company $S$, and a regulator $R$ (the PUC). We also model a vertically integrated utility company $U$ that is subject to regulation by $R$ (which makes decisions on behalf of $U$ ).

Our base case scenario is one with no solar systems: all customers depend on $U$ to satisfy their electricity demand. Customers are subject to flat-rate (rather than time-of-use, for tractability reasons) pricing. After $S$ makes its product available, customers may continue to depend solely on $U$ for their electricity or can install solar systems, thereby reducing their dependence on $U$. We study how $R$ 's regulatory actions influence social welfare moving from the base case to the with-solar scenario. $R$ 's social welfare measure accounts for financial and environmental considerations. However, customers and $S$ are self-interested, maximizing their own financial objectives. Specifically:

Customers are heterogeneous, with different demands and potentials to generate solar electricity 
(e.g. because of heterogeneous roof space). We consider $I$ tiers of customers indexed by $i \in\{1 \ldots, I\}$. Customer tier $i$ has annual demand $d_{i} \mathrm{kWh}$. If a tier $i$ customer installs a solar system, this system would generate $g_{i} \mathrm{kWh}$ of electricity annually; a customer can estimate this using tools such as Google's Project Sunroof (Google, 2020). This customer has an excess generation (the amount of her generation that she does not consume) $e_{i} \leq g_{i}$; this excess generation is sold back to the utility grid. Modeling $e_{i}$ as a separate parameter allows us to capture any potential temporal relationship between generation and demand; a customer's demand and generation do not necessarily follow the same profile, and their temporal relationship, whatever it is, determines $e_{i}$. Thus, a tier $i$ customer depends on the utility for an amount of energy $d_{i}^{\prime}=d_{i}-\left(g_{i}-e_{i}\right)$ (her grid usage) and sells back an amount of energy $e_{i}$, yielding a net usage of $d_{i}^{\prime}-e_{i}=d_{i}-g_{i}$. At an individual level, we do not restrict a customer's excess $e_{i}$ to be less than her grid usage $d_{i}^{\prime}$. Indeed, numerous large utilities (for example Florida Power \& Light and Georgia Power) do not place caps on how much electricity a customer can supply to the grid. An alternative model is followed by utilities such as Duke Energy Carolinas, that do not allow customers to supply more excess in a year than their annual grid usage. We discuss how our model can accommodate this alternative case in Section 4.4. We arrange customer tiers in order of increasing generation, so that $g_{i} \leq g_{i+1}$ (ties may be broken using the $d_{i}$ values). We let $h_{i}$ denote the number of tier $i$ households. A type $i$ household has an adopt/do not adopt decision $s_{i}$; $s_{i}$ takes the value of 1 if the customer chooses to adopt solar and 0 otherwise. We use $\vec{z}$ to denote an adoption outcome, i.e., $\vec{z}$ is an ordered tuple of $s_{i}$ values, $\forall i \in\{1, \ldots, I\}$. In Section 4.4, we extend our base formulation of customers in several ways. In our base model:

- All customer parameters are assumed to be fixed and known with certainty by all decision making entities. Our model may be extended to accommodate uncertainty in $d, g$, and $e$.

- We model a customer's demand $d_{i}$ as being insensitive to price. This assumption is driven by findings that electricity demand is fairly inelastic: A $1 \%$ change in price causes about $-0.39 \%$ change in electricity demand and $44 \%$ of households exhibit no short-run demand sensitivity to changes in the marginal price of electricity (Reiss and White, 2005). Our model can be extended to accommodate price-sensitive demand.

- All households in a tier make the same adoption decision. This assumption may be relaxed.

The Solar Company is a self-interested, monopolistic entity that sets prices for its solar systems. We show in Section 4.4 that our main results extend to a solar industry with Cournot competition.

We assume that solar panels are infinitely divisible (i.e., we ignore roof topography). $S$ 's decision variable is $p_{s}$, the price that a customer who adopts solar must pay to the solar company per unit of electricity she generates using the installed solar system. Solar companies offer such a contract 
(this is called a Power Purchase Agreement, or PPA), under which customers are only assessed a variable charge per $\mathrm{kWh}$ of generation, rather than having to pay a lump-sum amount for system purchase and installation (SunRun, 2019). Once set, $p_{s}$ is assumed to remain fixed. Customers in the U.S. can avail themselves of an investment tax credit of $30 \%$ on solar system purchases (Office of Energy Efficiency \& Renewable Energy, 2020). This credit has begun to ramp down starting in 2019 (Office of Energy Efficiency \& Renewable Energy, 2020); we therefore ignore it in our base model. In Section 4.4, we show how our model may easily be adjusted to accommodate this. Corresponding to this per-unit price $p_{s}, S$ incurs a cost of $c_{s}^{(y)}$ per kWh of generation that it sells, where $y$ is the total annual amount of generation sold to customers. This cost takes into account the manufacturing and sales costs that $S$ incurs. We assume that $c_{s}^{(y)}$ is non-increasing in $y$, to reflect the economies of scale enjoyed by $S$.

As an alternative to the PPA model, customers could purchase solar panels outright, paying a fixed cost for adoption and a variable cost that depends on the number of panels she purchases. Capturing this alternative requires considerable modifications to our model and analysis. We discuss these modifications and show how our main results continue to hold in Appendix A.2.

The Regulator is a socially interested party, $R$, whose decision is a tariff function $T\left(d^{\prime}, e, s\right)$ that governs the amount of money that the utility company charges a customer who draws an amount of energy $d^{\prime} \mathrm{kWh} /$ year from the grid, sells back $e \mathrm{kWh} /$ year to the grid and either adopts solar $(s=1)$, or does not adopt solar $(s=0)$. Note that both $d^{\prime}$ and $e$ are measurable by $U$ with an appropriate metering system. Also observe that if $s=0, d^{\prime}=d$ and $e=0$.

The Utility Company, $U$, operates in a regulated electricity market; it has a designated service territory in which it operates as a monopoly. It faces a fixed maintenance cost $f_{u}$ and an average per unit cost of electricity $c_{u}^{(x)} / \mathrm{kWh}$, where $x$ is the amount of electricity supplied by the utility company's sources (as opposed to rooftop solar). We impose no dependency of $c_{u}^{(x)}$ on $x$; therefore, this framework allows us to capture (i) the non-linear cost functions that utility companies typically face as the amount and timing of electricity they supply alters the mix of generation sources they use; and (ii) the dependence of the utility's generation economics on the specific temporal load profiles of their customers. The utility company uses its existing architecture to redistribute excess generation that it purchases from customers.

Let Period 0 be the base case scenario, when no households have rooftop solar. Under the Period 0 tariff structure, customers pay a per unit energy cost of $p_{r 0}$ and an annual fixed cost that we normalize to 0 , without loss of generality. We use this particular base case tariff structure for simplicity, but our approach readily extends to other common base case tariff structures; we 
demonstrate this using the example of New Mexico, where customers face tiered rates in Period 0 ) in Section 5. In Period 1, $R$ imposes tariff structure $T(\cdot)$. In response to tariff $T(\cdot), S$ sets a per unit solar rate $p_{s}$ in Period 2. In Period 3 individual customers, with knowledge of their demand $d_{i}$, generation capability $g_{i}$, and potential excess $e_{i}$ observe the tariff $T(\cdot)$ and the solar price $p_{s}$ and then endogenously decide to adopt $\operatorname{solar}\left(s_{i}^{*}=1\right)$ or not $\left(s_{i}^{*}=0\right)$. Each agent's decision is taken anticipating other agents' responses in future periods.

For notational convenience, we use $z$ in the superscript of a parameter, without parentheses, to denote the value the parameter takes under adoption outcome $\vec{z}$. For instance, the utility unit cost corresponding to adoption outcome $z$ is denoted $c_{u}^{z}$. Similarly, let the superscript 0 represent the no-adoption scenario, i.e., the base case. Thus $E^{0}=\sum_{i=1}^{I} h_{i} d_{i}$ is the total amount of energy that customers demand from the utility in the base case, and $E^{z}=E^{0}-\sum_{i=1}^{I} s_{i} h_{i} g_{i}$ as the corresponding quantity under adoption outcome $\vec{z}=\left(s_{1}, s_{2}, \ldots, s_{I}\right)$. We assume that all excess rooftop electricity can be redistributed to other customers, i.e., that the total grid usage is no less than the total excess supplied to the grid. Formally, we assume that $\sum_{i=1}^{I} h_{i}\left(s_{i}\left(d_{i}-g_{i}+e_{i}\right)+\left(1-s_{i}\right) d_{i}\right) \geq \sum_{i=1}^{I} h_{i} s_{i} e_{i} \Leftrightarrow$ $\sum_{i=1}^{I} h_{i} d_{i} \geq \sum_{i=1}^{I} h_{i} s_{i} g_{i}$. We restrict our attention to adoption outcomes $\vec{z}$ that satisfy this property. We define $\Delta_{E}^{z}=\sum_{i=1}^{I} s_{i} h_{i} g_{i}$ as the amount of rooftop solar adoption under outcome $\vec{z}$.

The decision-making entities in our model have the following objectives:

Customers wish to minimize their spend on electricity. Therefore, a tier $i$ customer solves:

$$
\min _{s_{i} \in\{0,1\}}\left(1-s_{i}\right) T\left(d_{i}, 0,0\right)+s_{i}\left(T\left(d_{i}^{\prime}, e_{i}, 1\right)+p_{s} g_{i}\right) .
$$

The Solar Company wishes to maximize profit by choosing solar price $p_{s}$ :

$$
\max _{p_{s}}\left(p_{s}-c_{s}^{z}\right) \Delta_{E}^{z}
$$

where $z$ is the adoption decision consistent with solar price $p_{s}$ and the given tariff $T(\cdot)$.

The Regulator wishes to maximize social welfare improvement, subject to considerations on solar company profitability, utility viability, and customer equity, that we discuss in Section 4 . We will consider two components of this social welfare improvement: Financial and Environmental.

(1) Financial: Since all cash flows except the purchase of electricity at $\operatorname{costs} c_{u}^{z}$ and $c_{s}^{z}$ occur between parties, they can be ignored. The net decrease in cash flows out of the system (the financial welfare improvement of the system) is therefore $c_{u}^{0} E^{0}-c_{u}^{z} E^{z}-c_{s}^{z} \Delta_{E}^{z}=\left(c_{u}^{0}-c_{u}^{z}\right) E^{0}+\left(c_{u}^{z}-c_{s}^{z}\right) \Delta_{E}^{z}$.

(2) Environmental: The regulator considers the environmental benefit accrued by sourcing $\Delta_{E}^{z} \mathrm{kWh}$ of energy from rooftop solar rather than from the utility. Let $m_{u}^{(x)}$ be the (monetized) average environmental cost of the utility generating one $\mathrm{kWh}$ of electricity when the total amount it 
generates is $x$, and $m_{s}$ be the (monetized) environmental cost of a rooftop solar panel generating one $\mathrm{kWh}$ of electricity (this does not depend on the total amount of electricity generated by rooftop solar). Using $x$ to parametrize $m_{u}^{(x)}$ allows us to capture the non-linear relationship between environmental cost and amount of electricity supplied by the utility. This environmental cost can, for instance, be estimated using the social cost of carbon and other particulate matter emissions.

We include both these considerations and write $R$ 's objective function as:

Problem $\mathcal{P}_{1}$ :

$$
\max _{\vec{z}} \underbrace{c_{u}^{0} E^{0}-c_{u}^{z} E^{z}-c_{s}^{z} \Delta_{E}^{z}}_{\Delta_{W F}=\text { Financial Welfare Improvement }}+\underbrace{m_{u}^{0} E^{0}-m_{u}^{z} E^{z}-m_{s} \Delta_{E}^{z}}_{\Delta_{W E}=\text { Environmental Welfare Improvement }} .
$$

The financial benefit from solar adoption crucially depends on the values of $c_{u}^{z}$ and $c_{u}^{0}$ relative to $c_{s}^{z}$. Solar production typically peaks around mid-day, creating the so-called duck curve (Jeff, St. John, 2016), and thus does not generally shave off peak load (which typically occurs in the early evening) or displace the base load generators during low load periods (early in the morning). We estimate levels of $c_{u}^{z}$ and $c_{s}^{z}$ in Section 5 and find that $c_{s}^{z}$ is typically higher than $c_{u}^{z}$ unless rooftop solar exclusively displaces the most expensive electricity sources. Therefore, we expect $\Delta_{W F}$ to be negative. Inducing an outcome with negative improvement in financial welfare $\Delta_{W F}$ implicitly acknowledges that there is a financial cost that society must bear in order to achieve stronger improvements in environmental welfare, represented in our model as $\Delta_{W E}$. As technological improvements cause $c_{s}^{z}$ to drop, the sign of $\Delta_{W F}$ could flip. Our model is robust to either case.

It is worth pointing out that although we do not explicitly model the decisions of the utility company, we implicitly capture any capacity changes that the utility company would need to make in response to solar adoption through the parameters $c_{u}^{z}$ and $m_{u}^{z}$ : since these depend on $\vec{z}$, the impact of these capacity decisions on utility and system welfare are captured. Note also that the regulator's social welfare optimization problem $\mathcal{P}_{1}$ depends on the tariff function only through the adoption outcome $\vec{z}$ that it induces. Therefore, we can break the regulator's problem into two steps. In the first step, the regulator finds the adoption outcome $\vec{z}$ that maximizes social welfare improvement by solving optimization problem $\mathcal{P}_{1}$. In the second step, the regulator seeks a tariff function to induce this optimal adoption outcome. Finding the optimal adoption outcome of $\mathcal{P}_{1}$, $\vec{z}^{*}$, requires estimating the values of $m_{u}^{z}$ and $c_{u}^{z}$ for all feasible adoption outcomes $\vec{z}$, unless $m_{u}^{z}$ and $c_{u}^{z}$ have some special structure that can be used. Let $\vec{z}^{*}$ be the resulting optimal adoption outcome.

The remainder of our analysis tackles how (and whether) the regulator can induce adoption outcome $\vec{z}^{*}$ by appropriately choosing tariff $T(\cdot)$, taking into account customer equity, solar company profitability, and utility company viability. We focus on the case where $\vec{z}^{*}$ specifies that at least one tier of customer adopts solar, as otherwise the inducement problem is trivial. 


\section{Inducing the Optimal Adoption Outcome}

We first discuss the considerations that $R$ must take into account when inducing adoption outcome $\vec{z}^{*}$ and then use these to formulate the regulator's inducement problem. For notational convenience we use $s_{i}^{*}$ as shorthand for the value of $s_{i}$ under outcome $\vec{z}^{*}$.

1. Utility viability: The regulator must ensure a specified rate-of-return to the utility company.

We denote the target (possibly negative) change in utility profit going from the base case to the with-solar case as $\Delta_{U}$. We represent this as a constraint in $R$ 's inducement problem:

$$
\sum_{i=1}^{I} h_{i}\left(s_{i}^{*} T\left(d_{i}^{\prime}, e_{i}, 1\right)+\left(1-s_{i}^{*}\right) T\left(d_{i}, 0,0\right)-c_{u}^{z^{*}} E^{z^{*}}\right)-\left(p_{r 0}-c_{u}^{0}\right) E^{0}=\Delta_{U}
$$

2. Solar company profitability: $R$ must ensure that $S$ earns sufficient profit $\Delta_{S}$; we assume $\Delta_{S}>0$. We model this as an equality constraint in $R$ 's inducement problem: for a fixed $\vec{z}^{*}$ and $\Delta_{U}$, allowing $S$ to earn more than the target $\Delta_{S}$ negatively impacts customers.

$$
\left(p_{s}-c_{s}^{z^{*}}\right) \Delta_{E}^{z^{*}}=\Delta_{S}
$$

3. Customer equity: Since $R$ is also responsible for customer equity she would like to minimize the maximum increase in cash outflow seen by any tier of customer. This is a common fairness criterion used in game theory and ethics credited to Rawls (Rawls, 1974). If this objective is non-positive, then all tiers of customers (weakly) benefit from the introduction of solar and there is no cross-subsidization. We treat this as the objective function of $R$ 's inducement problem; $R$ seeks the tariff $T(\cdot)$ that will induce the optimal $\vec{z}^{*}$ that satisfies:

$$
\min _{T(\cdot)} \max _{i} s_{i}^{*}\left(T\left(d_{i}^{\prime}, e_{i}, 1\right)+p_{s} g_{i}\right)+\left(1-s_{i}^{*}\right) T\left(d_{i}, 0,0\right)-p_{r 0} d_{i} .
$$

Define $\Delta_{C}=\sum_{i=1}^{I} p_{r 0} d_{i}-s_{i}^{*}\left(T\left(d_{i}^{\prime}, e_{i}, 1\right)+p_{s} g_{i}\right)-\left(1-s_{i}^{*}\right) T\left(d_{i}, 0,0\right)$ as the total improvement in financial welfare of the customer base. Observe that the total change in financial welfare $\Delta_{W F}=\Delta_{S}+$ $\Delta_{U}+\Delta_{C}$. Therefore, if $\Delta_{W F}$ is negative, our imposition that $\Delta_{S}$ be positive requires that either (i) the utility company makes a lower profit (leading to $\Delta_{U}<0$ ); or (ii) $\Delta_{C}<0$, implying that at least one tier of customer is worse off. Note, however, that the $\Delta_{W F}<0$ solution will only emerge if it is optimal to sacrifice financial welfare in favor of environmental welfare. Furthermore, as mentioned above, technological developments leading to lower-cost rooftop solar could eventually cause $\Delta_{W F}>0$. This will allow us to achieve an outcome where all parties (the utility company, the solar company, and customers as a whole) can be made financially better off.

In order to formally write out the regulator's inducement problem, we first examine the optimization problem of a tier $i$ customer, as specified in (1). Such a customer favors adopting solar 
if and only if $p_{s} \leq \frac{T\left(d_{i}, 0,0\right)-T\left(d_{i}^{\prime}, e_{i}, 1\right)}{g_{i}} \triangleq t(i)$ (we break ties in favor of adoption). Thus specifying $T(\cdot)$ determines the $t(i)$ values and also induces an ordering among them. For a given solar price $p_{s}$ the set of tiers that adopt is $\left\{i: t(i) \geq p_{s}\right\}$.

Now consider $S$ 's pricing decision. The optimal choice of $p_{s}$ for $S$ must be $t(i)$ for some $i \in\{1, \ldots, I\}$ : If $S$ chose some price $p_{s}$ between $t(i)$ and $t(j)$ for some $i$ and $j$ such that $t(j)=\min _{k} t(k): t(k)>p_{s}$, then choosing price $t(j)$ increases $S$ 's margin and does not alter her volume (see equation $(2)$ ). Therefore, $S$ 's optimization problem reduces to choosing an $i^{*}$ such that the profit obtained by setting $p_{s}=t\left(i^{*}\right)$ is larger than the profit obtained from all other choices $j \neq i^{*}$ or choosing $p_{s}>$ $\max _{i} t(i)$. Note that all adopting customers pay $p_{s} ; t(i)$ is simply a threshold value of $p_{s}$ up to which a tier $i$ customer is induced to adopt solar.

Define the adoption set $A^{*}=\left\{i: s_{i}^{*}=1\right\}$. In order to induce adoption outcome $\vec{z}^{*}, p_{s}$ must be chosen so that $t(i) \geq p_{s}$ iff $i \in A^{*}$. Define a tier $i$ to be 'marginal' if $p_{s}=t(i)$. Let $M$ be the set of indices of the marginal adopting tiers. We focus on the case of $|M|=1$ for expositional convenience, although our analysis will easily generalize; let $m$ be the index of the marginal tier. We can now pose $R$ 's inducement problem, folding in the household and solar company decisions as follows:

$$
\min _{T(\cdot)} \max _{i} s_{i}^{*}\left(T\left(d_{i}^{\prime}, e_{i}, 1\right)+t(m) g_{i}\right)+\left(1-s_{i}^{*}\right) T\left(d_{i}, 0,0\right)-p_{r 0} d_{i}
$$

Subject to constraints:

$$
\begin{aligned}
& t(i)=\frac{T\left(d_{i}, 0,0\right)-T\left(d_{i}^{\prime}, e_{i}, 1\right)}{g_{i}}, \quad \forall i \\
& \sum_{i=1}^{I} h_{i}\left(s_{i}^{*} T\left(d_{i}^{\prime}, e_{i}, 1\right)+\left(1-s_{i}^{*}\right) T\left(d_{i}, 0,0\right)-c_{u}^{z^{*}} E^{z^{*}}\right)-\left(p_{r 0}-c_{u}^{0}\right) E^{0}=\Delta_{U} \\
& \left(t(m)-c_{s}^{z^{*}}\right) \Delta_{E}^{z^{*}}=\Delta_{S} \\
& \left(t(i)-c_{s}^{z_{i}}\right) \sum_{j=1}^{I} \mathbb{I}_{t(j) \geq t(i)} h_{j} g_{j}<\Delta_{S}, \quad \forall i: t(i) \neq t(m) \\
& t(i) \geq t(m), \quad \forall i \in A^{*} \\
& t(i)<t(m), \quad \forall i \notin A^{*}
\end{aligned}
$$

Here, (8) defines $t(i)$ in terms of the regulator's decision variables, (9) ensures that $U$ receives the specified rate of return implied by $\Delta_{U}$ and (10) ensures that $S$ achieves the specified profit $\Delta_{S}$ by choosing solar price $t(m)$. With some abuse of notation, we let $c_{s}^{z_{i}}$ denote $S$ 's unit cost when the price $p_{s}$ is set to $t(i)$ and the adopting tiers are $j: t(j) \geq t(i)$. Then, (11) forms a set of incentive 
compatibility (IC) constraints, which ensure that $S$ cannot make a higher profit than $\Delta_{S}$ by setting $p_{s}=t(i)$ for $t(i) \neq t(m)^{2}$. Constraints (12)-(13) induce only customers in $A^{*}$ to adopt solar.

This formulation is not immediately amenable to analysis because (11) has an indicator function. Therefore, as discussed in Section 3, we solve the problem in two steps. As our first step, we find the optimal solution $\vec{z}^{*}$ of $\mathcal{P}_{1}$. For our second step, we:

1. Enumerate all underlying orderings over the $t(i)$ values that would result in adoption outcome $\vec{z}^{*}$. These can be obtained by permuting the ordering of adopters (which we can do in exactly $\left|A^{*}\right|$ ! different ways), and for each of these orderings, permuting the non-adopters (which we can do in $\left(I-\left|A^{*}\right|\right)$ ! different ways). For example, if $I=4$, and $\vec{z}^{*}$ specifies that tiers 1 and 3 adopt, the possible orderings are: (i) $t(2) \leq t(4)<\boldsymbol{t}(\mathbf{1}) \leq t(3)$, (ii) $t(2) \leq t(4)<\boldsymbol{t}(\mathbf{3}) \leq t(1)$, (iii) $t(4) \leq t(2)<\boldsymbol{t}(\mathbf{1}) \leq t(3)$, and (iv) $t(4) \leq t(2)<\boldsymbol{t}(\mathbf{3}) \leq t(1)$. The threshold in bold corresponds to the marginal adopter and a strict inequality separates the adopters and non-adopters. Let $O^{*}$ be the set of these orderings and let $o$ refer to a specific ordering in $O^{*}$. Let $o(j)$ denote the position of tier $j$ in ordering $o, j \in\{1,2, \ldots, I\}$ and $m(o)$ denote the marginal adopter under $o$.

2. Solve $\left|O^{*}\right|$ different optimization problems, one to induce each possible ordering. We call this problem $\mathcal{P}_{2}$. We then choose an ordering with the best objective value.

We can now formally write the inducement problem $\mathcal{P}_{2}$ as follows:

Problem $\mathcal{P}_{2}$ :

$\min _{T(\cdot)} \max _{i} s_{i}^{*}\left(T\left(d_{i}^{\prime}, e_{i}, 1\right)+t(m(o)) g_{i}\right)+\left(1-s_{i}^{*}\right) T\left(d_{i}, 0,0\right)-p_{r 0} d_{i}$

Subject to constraints:

$$
\begin{aligned}
& t(i)=\frac{T\left(d_{i}, 0,0\right)-T\left(d_{i}^{\prime}, e_{i}, 1\right)}{g_{i}}, \forall i \\
& \sum_{i=1}^{I} h_{i}\left(s_{i}^{*} T\left(d_{i}^{\prime}, e_{i}, 1\right)+\left(1-s_{i}^{*}\right) T\left(d_{i}, 0,0\right)-c_{u}^{z^{*}} E^{z^{*}}\right)-\left(p_{r 0}-c_{u}^{0}\right) E^{0}=\Delta_{U}
\end{aligned}
$$

$t(i)$ ordering consistent with $o$

$$
\begin{aligned}
& \left(t(m(o))-c_{s}^{z^{*}}\right) \Delta_{E}^{z^{*}}=\Delta_{S} \\
& \left(t(i)-c_{s}^{z_{i}}\right) \sum_{j=1}^{I} \mathbb{I}_{o(j)>o(i) \text { in ordering } o} \cdot h_{j} g_{j}<\Delta_{S}, \forall i \neq m(o)
\end{aligned}
$$

Here, the set of inequalities referred to by (17) is $t(i) \leq t(j), \forall i, j: o(j)=o(i)+1, i \neq m(o) ; t(i)<$ $t(j)$, for $i=m(o), o(j)=o(i)+1$. We discuss this formulation further in Appendix B.1.

${ }^{2}$ We model these IC constraints as being strict rather than weak, because if $S$ deviates to a price $p_{s} \neq t(m)$, the outcome induced is different from the desired $z$. We will show in Sections 4.2-4.3 that if the tariff structure is appropriately chosen, this strict inequality does not impair the feasibility of the problem. 
$\mathcal{P}_{1}$ always has a solution because it is unconstrained. However, whether $\mathcal{P}_{2}$ is feasible is unclear: the tariff must ensure that all constraints including the set of IC constraints (19) and the ordering constraints (17) can hold together. This motivates our central question: Let $\mathcal{T}$ be the set of allowable tariff functions from which $T(\cdot)$ must be chosen. How does the choice of $\mathcal{T}$ affect the feasibility of $\mathcal{P}_{2}$ ? Further, if $\mathcal{T}$ yields a feasible $\mathcal{P}_{2}$, can it induce an outcome free from cross-subsidization?

Definition 1. Cross-subsidization (CS): An outcome features CS if the objective value of $\mathcal{P}_{2}$ is positive; i.e., at least one tier of customer is financially worse off in the with-solar case.

For an outcome to be free from CS requires that $\Delta_{C}=\Delta_{W F}-\Delta_{S}-\Delta_{U} \geq 0$. We examine how different choices of $\mathcal{T}$ affect the regulator's ability to induce outcomes free from CS when $\Delta_{C} \geq 0$; specifically, is $\Delta_{C} \geq 0$ sufficient to induce such a CS-free outcome?

\subsection{Non-tiered tariffs that discriminate between adopters and non-adopters}

Many states in the U.S. (including Nevada, which we examine more closely in Section 5) have utility companies that administer non-tiered rate schedules for residential customers. Non-tiered tariff structures have the benefit of being simple to administer and therefore simple to modify in the rate case proceedings, the process by which utility companies petition for rate changes to the PUC. These non-tiered structures can, however, discriminate between solar adopters and non-adopters, i.e., these two types of customers may be subject to different rate schedules, as is the case with NV Energy's 2016 tariff in Nevada. We study such rate structures in this section.

Let $\mathcal{T}_{1}$ be the set of linear, non-tiered tariff structures that discriminate between adopters and non-adopters, i.e., they are on different rate schedules. $\mathcal{T}_{1}$ has the following general specification:

$$
T(d, 0,0)=r_{d} d+r_{0} ; T\left(d^{\prime}, e, 1\right)=s_{d} d^{\prime}+s_{e} e+s_{0}
$$

We prove the following propositions. All proofs appear in Appendix A.1.

Proposition 1. Tariff structure $\mathcal{T}_{1}$ cannot guarantee the feasibility of $\mathcal{P}_{2}$ : There exist parameters and outcomes $\left\{\vec{z}^{*}, \Delta_{S}, \Delta_{U}\right\}$ for which $\mathcal{P}_{2}$ is not feasible for any ordering o.

Proposition 1 implies that $\mathcal{P}_{2}$ does not always have a solution under tariff structure $\mathcal{T}_{1}$. While this is discouraging, the following proposition shows that under a restriction on $\vec{z}^{*}$ there does exist a feasible solution to $\mathcal{P}_{2}$, if we drop the IC constraints.

Proposition 2. In the absence of the IC constraints (11), there exists an ordering o for which tariff structure $\mathcal{T}_{1}$ guarantees the feasibility of $\mathcal{P}_{2}$ if $A^{z^{*}}=\left\{i^{*}, i^{*}+1, \ldots, I\right\}$ for some $i^{*}$.

Proposition 2 has an important practical implication: if the solar price $p_{s}$ were also controlled by the regulator $R$, and $\vec{z}^{*}$ prescribes that a contiguous block of high-generation customer tiers adopts, 
a linear tariff structure with non-tiered rates would suffice to satisfy the constraints of $\mathcal{P}_{2}$, as the regulator would not have to contend with IC constraints (11). Alternatively, if the utility company itself offered rooftop solar rather than an outside firm, the IC constraints could be ignored (as the solar price set by $U$ would now be subject to regulation) with equation (9) suitably modified.

The intuition for this tariff's failure to achieve feasible outcomes in general is its limited ability to transfer welfare among customers in different tiers. In particular, its ability to make solar attractive to some tiers and not to others while retaining IC for $S$ is impaired by not having tier-dependent parameters. While dropping the IC constraints leads to a special feasible case, the current environment in the U.S. is one with unregulated solar companies. Therefore, a richer class of tariff structures is in general required. Furthermore, as we shall see in Section 5, even in cases when $\mathcal{P}_{2}$ is feasible, $\mathcal{T}_{1}$ achieves poor CS outcomes.

\subsection{Tiered tariffs that discriminate between adopters and non-adopters}

In states such as New Mexico (which we study in detail in Section 5) and Washington, the PUCs have mandated that solar customers may not be assessed any additional standby, capacity, interconnection, or other fee or charge by the utility (NC Clean Energy Technology Center, 2017, 2019). This implies that tariffs in these states may be tiered, but must operate under a single rate schedule and feature retail net-metering: If the utility repurchased electricity at less than their retail rate this would be considered a fee to solar adopters. Let $\mathcal{T}_{2}$ be the set of such tariffs.

Under such a tariff structure, the appropriate rate class (not to be confused with usage tier $i \in\{1,2, \ldots, I\})$ in the rate schedule is applied based on a household's net demand (this net demand is $d-g$, where $g>0$ iff they adopt solar). For instance, if a tier 1 household does not adopt solar, demands an amount of electricity $d_{1}$, and is placed in rate class 1 , a tier 2 household who adopts solar and has a net demand of $d_{2}-g_{2}=d_{1}$ also falls into rate class 1 , and is billed as such.

Let $C=\{1,2, \ldots,|C|\}$ be the set of indices corresponding to rate classes in $U$ 's rate schedule. Arrange this set in order of increasing (net) demand, i.e., rate class 1 corresponds to the lowest net demand and rate class $|C|$ corresponds to the highest net demand. In order to support customers making endogenous solar adoption decisions, this rate schedule must contain enough rate classes to support any possible adoption/non-adoption decision by customers. Therefore, $|C| \geq I+1$.

It suffices to consider the tariff function $T\left(d^{\prime}, e, s\right)=T(c)=r_{c} n_{c}$, where $c$ is the index of the rate class associated with net demand $n_{c} ; n_{c}=d$ for a non-adopter and $n_{c}=d^{\prime}-e=d-g$ for an adopter. This tariff function is fully defined by choosing $r_{c}, \forall c \in C$. Having a fixed cost $f_{c}$ that also depends on class $c$ reduces to our function by modifying $r_{c}$ to offset $f_{c}, \forall c$. 
Proposition 3. Corresponding to every ordering o and outcome $\vec{z}^{*}$, there exists a feasible rate schedule $\left(r_{c}\right)$, i.e., a tariff of type $\mathcal{T}_{2}$, that satisfies the constraints of $\mathcal{P}_{2}$.

While this tariff structure can always feasibly induce an outcome characterized by $\left\{\vec{z}^{*}, \Delta_{S}, \Delta_{U}\right\}$, unfortunately, it cannot guarantee a CS-free outcome when $\Delta_{C} \geq 0$.

Proposition 4. A tariff of type $\mathcal{T}_{2}$ cannot guarantee CS-free outcomes: there exist parameters and outcomes $\left\{\vec{z}^{*}, \Delta_{S}, \Delta_{U}\right\}$ for which no CS-free outcome can be generated even when $\Delta_{C} \geq 0$.

While tariff structure $\mathcal{T}_{2}$ is simple and guarantees feasibility, it cannot guarantee desirable properties with respect to customer equity. Intuitively, this tariff fares better than tariff structure $\mathcal{T}_{1}$ because its tiered nature allows welfare transfer among tiers. However, its ability to shield customers from cross-subsidization is limited by the fact that adopters and non-adopters may be grouped into the same tier. Therefore, a tariff structure that can guarantee CS-free outcomes must (at least) be able to discriminate between solar adopters and non-adopters by placing them in different rate schedules.

\subsection{Tiered tariffs that differentiate between adopters and non-adopters}

We now consider a tiered tariff structure that presents different rate schedules to solar and non-solar customers. Both these attributes are present in the tariff structure operated by Arizona's APS, where all customers face tiered rates and solar customers pay a grid access charge in proportion to the size of their solar installation (APS Energy, 2019). We propose and study a slightly simpler tariff structure $\mathcal{T}_{3}$ : one that is non-tiered for non-adopters ${ }^{3}$ and tiered for adopters. Under our structure, solar and non-solar customers are charged the same uniform variable energy charge based on their net energy consumption (we implicitly prescribe retail net-metering), but a solar customer is also assessed a fixed annual charge that depends on her tier $i$. This is equivalent, but easier to analyze than the more common practice of the energy charge (rather than the fixed cost) depending on the customer's tier. Thus $\mathcal{T}_{3}$ has the following general specification:

$$
T\left(d_{i}, 0,0\right)=p_{r} d_{i} ; T\left(d_{i}^{\prime}, e_{i}, 1\right)=p_{r}\left(d_{i}^{\prime}\right)-p_{r}\left(e_{i}\right)+f_{i}=p_{r}\left(d_{i}-g_{i}\right)+f_{i} .
$$

Note that $U$ can infer a solar customer's tier by observing the value of $d_{i}^{\prime}$, the energy drawn from the grid, and contract on a fixed cost based on this amount.

Because this tariff structure has more parameters than $\mathcal{T}_{1}$, it might at first seem intuitive (and trivial) that this structure guarantees the feasibility of $\mathcal{P}_{2}$ : one could correctly observe that the

\footnotetext{
${ }^{3}$ If the Period 0 tariff structure is tiered rather than having the same rate $p_{r 0}$ apply to all customers, our proposed
} tariff structure would require that non-adopters also face tiered rates. 
fixed costs for adopting tiers $i$ can be chosen arbitrarily to adjust $\Delta_{U}$ appropriately. However, it is not so simple. The fixed costs must also result in the prescribed solar price of $p_{s}=t(m)$ being incentive compatible for $S$ : picking $p_{s} \neq t(m)$ must result in a smaller profit (see (19)) than the profit from picking $p_{s}=t(m)$. This deviation can be made sufficiently unattractive by ensuring that $t(i)$ for $i \neq m$ are low enough; $R$ can achieve this by manipulating the values of $f_{i}, i \neq m$ (under $\left.\mathcal{T}_{3}, t(i)=p_{r}-f_{i} / g_{i}\right)$. But this imposes restrictions on the fixed costs $f_{i}$. Nevertheless, our proposed two-part tariff, like $\mathcal{T}_{2}$, guarantees the feasibility of $\mathcal{P}_{2}$. Furthermore, it can also guarantee no CS if $\Delta_{C} \geq 0$.

We prove these properties using a specific version of our tariff, $T^{*}$, constructed as follows:

1. Reorder the indices such that tiers $1 \ldots m-1$ do not adopt, and tiers $m, \ldots I$ adopt.

2. Let $c_{s}^{z_{A} l l}$ be the lowest possible value of $c_{s}^{z_{i}}$, corresponding to all tiers adopting.

3. Set $t(m)=c_{s}^{z^{*}}+\Delta_{S} / \Delta_{E}^{z^{*}}, t(i)=c_{s}^{z} A l l, \forall i<m$, and $t(i)=t(m), \forall i>m$. Express the $f_{i}$ values according to the relationship $t(i)=p_{r}-f_{i} / g_{i} \Leftrightarrow f_{i}=g_{i}\left(p_{r}-t(i)\right), \forall i$.

4. Using these expressions for $f_{i}$, observe that (16) reduces to a single linear equation in $p_{r}$. Solve this equation to obtain $p_{r}$.

Proposition 5. (a) Corresponding to every ordering o and outcome $\left\{\vec{z}^{*}, \Delta_{S}, \Delta_{U}\right\}$, there exists a feasible tariff function of the form $\mathcal{T}_{3}$, namely $T^{*}$ that satisfies the constraints of $\mathcal{P}_{2}$.

(b) When $\Delta_{C} \geq 0$, tariff $T^{*}$ induces an outcome that is CS-free. Furthermore, if $\vec{z}^{*}$ prescribes that the lowest demand tier does not adopt solar, $T^{*}$ is the optimal solution to $\mathcal{P}_{2}$.

Tariff $T^{*}$ can easily be computed in closed form, and Proposition 5 shows that it is feasible for $\mathcal{P}_{2}$, and can guarantee no CS if $\Delta_{C} \geq 0$. Furthermore when the tier with the smallest demand does not adopt, $T^{*}$ provides the optimal solution to $\mathcal{P}_{2}$. Therefore, we restrict our attention to $T^{*}$.

It is natural to ask whether this tariff structure's superior performance is solely attributable to the number of degrees of freedom it offers to the regulator. The answer is no: While the non-tiered tariff structure $\mathcal{T}_{1}$ has only 5 parameters, the tiered-tariff structure $\mathcal{T}_{2}$ has $|C|$ parameters, where $|C| \geq I+1$. Tariff $T^{*}$ has exactly $I+1$ parameters, i.e., weakly fewer than $\mathcal{T}_{2}$.

Implementation as a buy-all, sell-all or feed-in-tariff: Another advantage of $T^{*}$ is apparent after some algebraic manipulation. Observe that under $T^{*}$ the fixed cost for adopting tiers $i \geq m$, is given by $f_{i}=\frac{f_{m}}{g_{m}} g_{i}$, that is, the fixed cost is proportional to the amount of generation. For nonadopting tiers $i<m$, the fixed cost is $g_{i}\left(p_{r}-c_{s}^{z_{A} \text { All }}\right)$, which again, is proportional to the amount of (potential) generation. We can therefore rewrite the tariff function as follows:

$$
T\left(d_{i}, 0,0\right)=p_{r} d_{i}
$$


Singh, Scheller-Wolf: That's Not Fair: Tariff Structures for Electric Utilities with Rooftop Solar

Table 1 Comparison of Tariff Structures

\begin{tabular}{c|c|c|c:c}
\hline & $\mathcal{T}_{1}$ & $\mathcal{T}_{2}$ & $\mathcal{T}_{3}$ & $T^{*}$ \\
\hline $\begin{array}{c}\text { Social Welfare: } \\
\text { Can induce target adoption } \\
\text { outcome to balance } \Delta_{W F} \text { and } \Delta_{W E}\end{array}$ & No & Yes & Yes & Yes \\
\hline $\begin{array}{c}\text { Cross-Subsidization: } \\
\text { Positive } \Delta_{W F} \text { allows } \\
\text { every tier to benefit }\end{array}$ & No & No & Yes & Yes \\
\hline $\begin{array}{c}\text { Easy to implement: } \\
\text { Does not require }\end{array}$ & $\begin{array}{c}\text { Yes } \\
\text { many free parameters }\end{array}$ & $\begin{array}{c}\text { No } \\
\text { params. }\end{array}$ & $\begin{array}{c}\text { Moderate } \\
I+1 \text { params. }\end{array}$ & $\begin{array}{c}\text { Yes } \\
\text { params. }\end{array}$ \\
\hline
\end{tabular}

$$
\begin{aligned}
& T\left(d_{i}^{\prime}, e_{i}, 1\right)=p_{r}\left(d_{i}-g_{i}\right)+\frac{f_{m}}{g_{m}} g_{i}=p_{r} d_{i}-\left(p_{r}-\frac{f_{m}}{g_{m}}\right) g_{i}=p_{r} d_{i}-p_{s} g_{i} \text { for } i \geq m \\
& T\left(d_{i}^{\prime}, e_{i}, 1\right)=p_{r}\left(d_{i}-g_{i}\right)+\left(p_{r}-c_{s}^{z}{ }^{z} l l\right) g_{i}=p_{r} d_{i}-c_{s}^{z_{A l l}} g_{i} \text { for } i<m
\end{aligned}
$$

Therefore, this tariff can be implemented as a simple buy-all, sell-all tariff with two different buyback rates; under such a tariff, a customer sells back all their generation to the grid and receives a specified rate for it. $T^{*}$ sets this rate at $p_{s}$ for adopting tiers and $c_{s}^{\text {All }}$ for non-adopting tiers (note that these non-adopting customers do not end up actually selling electricity back). This implementation is characterized by only three parameters: $p_{r}$, the buyback rate $p_{s}$ for adopting customers, and the buyback rate $c_{s}^{z}$ All for non-adopting customers.

Buy-all, sell-all tariffs (sometimes also called feed-in tariffs) have been proposed in Connecticut, Maine, and Indiana (State of Connecticut Public Utilities Commission, 2018, Kari Lyderson, 2017, State of Maine Public Utilities Commission, 2017). While the proposal is still on the table in Indiana, it has been repealed in Connecticut and Maine. Buy-all, sell-all tariffs are generally viewed as unfavorable to the solar industry because they represent a loss of autonomy of customers, i.e., all energy generated by them has to be sold back to the grid. However, such tariffs have significant international acceptance, particularly in Europe and the Asia-Pacific region: It is forecast that 38\% of global growth in the residential solar sector between 2019 and 2024 will come from customers on a buy-all, sell-all tariff scheme (IEA, 2019). Furthermore, we have seen that $T^{*}$ has an equivalent net-metering implementation. Finally, under this tariff, any net customer surplus (when $\Delta_{C} \geq 0$ ) is distributed to customers through a decrease in retail rate $p_{r}$, benefiting all customers.

Table 1 summarizes the comparison of tariff structures $\mathcal{T}_{1}, \mathcal{T}_{2}, \mathcal{T}_{3}$, and its special case $T^{*}$.

\subsection{Extensions}

Prohibiting net suppliers: If a utility caps a customer's annual excess to their grid usage, adopting customers supplied by such a utility would simply install fewer solar panels and thereby supply less excess. For instance, a customer with $d_{i}=8000, g_{i}=9000$ and $e_{i}=4000$ would simply 
install fewer solar panels, making $g_{i}=8000$ and $e_{i}=3000$, so that $d_{i}^{\prime}=e_{i}=3000$. Our numerical results are qualitatively unaltered if we disallow net suppliers.

Investment tax credit: Interpret $p_{s}$ as the discounted rate that customers pay for solar power; $S$ obtains revenue at a rate $\frac{p_{s}}{70 \%}$ per $\mathrm{kWh}$. All our results continue to hold under this modification.

Competition in the solar marketplace: Our model and analysis can be extended to competition in the solar marketplace by making suitable modifications to the solar profit equation (18) and IC constraints (19) in Problem $\mathcal{P}_{2}$. We model a marketplace where $\Gamma$ solar firms (indexed by $\gamma$ ) engage in symmetric Cournot competition, as in related literature (Goodarzi et al., 2019). Each firm $\gamma$ decides a quantity $q_{\gamma}$ to bring to market, and the market clears at price $P\left(\sum_{\gamma} q_{\gamma}\right)$, where $P(Q)$ is the usual inverse demand function.

For a given outcome $z^{*}$ and ordering $o$, the regulator requires that the market clears at price $t(m)$ with quantity $\Delta_{E}^{z^{*}}$ and that the solar profit (in this case, the total industry profit) is $\Delta_{S}$. Since the solar firms are symmetric, each firm brings a quantity of $\Delta_{E}^{z^{*}} / \Gamma$ to market under this equilibrium. We can restrict our attention to total quantities $Q$ that are consistent with the outcome $z^{*}$ and ordering $o$, i.e., total quantities $Q$ for which the market clears at price $t(i)$ for some $i$. In order to realize the required equilibrium, each firm must find it optimal to bring quantity $\Delta_{E}^{z^{*}} / \Gamma$ to market, given that all other firms do so. Define $b(i)=\sum_{j=i}^{I} h_{j} g_{j}-\Delta_{E}^{z^{*}} \frac{\Gamma-1}{\Gamma}$ as the amount of additional quantity that one solar firm needs to bring to the market so that the market clears at price $t(i)$. We replace solar profit equation (18) and IC constraints (19) by (25) and (26) respectively:

$$
\begin{aligned}
\left(t(m)-c_{s}^{z^{*}}\right) \frac{\Delta_{E}^{z^{*}}}{\Gamma} & =\frac{\Delta_{S}}{\Gamma} \\
\left(t(i)-c_{s}^{z_{i}}\right) b(i) & <\frac{\Delta_{S}}{\Gamma}, \forall i \neq m, b(i)>0 .
\end{aligned}
$$

Under this extension, tariff structure $T^{*}$ continues to be feasible, and satisfies Proposition 5. (The proof is identical.) We provide an illustrative numerical example in Appendix B.2.

Customer demand elasticity: We can adapt our model to a situation where demand is elastic to price. We let $\tilde{d}_{i}\left(\mu_{i}\right)$ denote the amount of electricity demanded by a tier $i$ customer, where $\mu_{i}$ is the average price she pays for consumed electricity (this includes payments to $U$ and $S$, which depend on $T(\cdot))$. Because the tariff chosen by the regulator affects the amount of electricity demanded by customers, the financial and environmental objectives in $\mathcal{P}_{1}$ are, in turn, affected. In particular, choosing adoption outcome $z$ no longer specifies $c_{u}^{z}$ because the amount of electricity that a tier $i$ customer demands (and hence the total demand supplied by the utility) now depends on the specific tariff implementation that realizes outcome $z$. Therefore, accommodating elastic demand requires us to revisit the decoupling of $\mathcal{P}_{1}$ and $\mathcal{P}_{2}$. Under some simple regularity conditions on 
the function $\tilde{d}_{i}\left(\mu_{i}\right)$, we show that $T^{*}$ continues to satisfy Proposition 5 . We present all details in Appendix A.9.

Customer parameter uncertainty: In practice, households' usage and generation parameters are random variables. We can relax our deterministic assumption by allowing individual households to draw $d, g$, and $e$ from a discrete distribution with $I$ points in its support. We define a joint probability mass function $\phi(d, g, e)$ over the space of possible values of $d, g$, and $e$ and index the support of $\phi(\cdot)$ by $i$. Now, $h_{i}=H * \phi\left(d_{i}, g_{i}, e_{i}\right)$, where $H$ is the total number of households. In expectation $h_{i}$ customers will have demand $d_{i}$, generation $g_{i}$ and excess $e_{i}$. We can now reformulate problems $\mathcal{P}_{1}$ and $\mathcal{P}_{2}$ in terms of expectations.

Heterogeneous adoption decisions within a tier: For various reasons including capital liquidity and inertia to change, some customers belonging to a tier induced to adopt solar might not actually adopt. Let $\pi_{i}$ be an exogenously given expected fraction of households in tier $i$ that would adopt solar if economically viable (endogenous determination of $\pi_{i}$ is beyond the scope of this model). The remaining $1-\pi_{i}$ fraction of households in tiers $i: s_{i}^{*}=1$ continue to fulfill their demand from the utility directly. We then reformulate our model by replacing $h_{i}$ by $\pi_{i} h_{i}$ in the solar profit equations, adjusting the utility company's rate-of-return equation appropriately, and modifying the objective of $\mathcal{P}_{2}$ to include non-adopters in tiers induced to adopt. All results related to $T^{*}$ continue to hold.

Strategic customer demand exaggeration to generate bill savings: It is undesirable for a tariff structure to incentivize a type $i$ customer to "spoof" a type $j$ customer by exaggerating her demand in order to generate bill savings, that is, having her total outflow (to $U$ and $S$ ) be reduced by spoofing another tier. Therefore, we must consider the four possible ways a customer type may spoof another customer type. We show how $\mathcal{P}_{2}$ can be modified to prevent this in Appendix A.3.

Strategic customer panel installation decisions to generate bill savings: It is undesirable to induce solar customers to install solar capacity smaller than $g_{i}$. Observe that if a tier $i$ customer's generation is reduced to $\tilde{g}_{i}<g_{i}$, her excess also is (weakly) reduced to some $\tilde{e}_{i} \leq e_{i}$. This might or might not alter her tier (which, recall, is measured by measuring her grid usage $d-(g-e)$ ). Suppose it does not result in a tier alteration. In this case we can impose the constraint $p_{s}<p_{r}$ so that installing less than capacity $g_{i}$ will increase a customer's bill. We shall see in Section 5 that for realistic parameter values $p_{s}<p_{r}$ holds because the prescribed fixed cost $f_{m}$ for the marginal tier $m$ is positive. If the customer was able to change her tier, and therefore, the applied fixed cost by installing panels to less than capacity, we need a treatment similar to the treatment for demand exaggeration. We describe the details in Appendix A.4. We shall see in Section 5 that for realistic parameter values, moving to a higher tier causes customers to incur higher fixed costs, and therefore, reducing $g_{i}$ - even to effect a change in tier - is not beneficial. 


\section{Numerical Analysis}

Using data from the states of Nevada and New Mexico - where regulatory changes threaten the rooftop solar industry - we study how the tariff structures in operation perform compared to $\mathcal{T}_{3}$. Our approach to estimating the parameters $d, g, e$, and $h$ is based on household micro-data from the U.S. Energy Information Administration's Residential Energy Consumption 2009 Survey (U.S. Energy Information Administration, 2009) ${ }^{4}$. We divide the set of households into four tiers in each state. In order to estimate $c_{s}, m_{s}, c_{u}^{z_{i}}$, and $m_{u}^{z_{i}}$ we use various sources of data: (i) the existing energy mix for each state; (ii) levelized financial cost estimates for each energy source; (iii) greenhousegas emissions estimates for each energy source; (iv) estimates of the social cost of carbon; and (v) estimates of the monetized impact of other environmental externalities, such as health costs associated with emissions like $\mathrm{SOx}, \mathrm{NOx}$ and particulate matter. A detailed discussion of all these estimation procedures is presented in Appendix A.5.

In Section 5.1, we use these parameters to run numerical experiments under a wide range of settings obtained by: (i) varying the energy source displaced by rooftop solar, thereby altering the solution to $\mathcal{P}_{1}$; (ii) changing how the financial surplus (or deficit) $\Delta_{W F}$ implied by $\mathcal{P}_{1}$ is split among $\Delta_{C}, \Delta_{S}$, and $\Delta_{U}$ thereby altering the solution to $\mathcal{P}_{2}$; and (iii) considering two solar market structures - monopolistic $(\Gamma=1)$ and competitive $(\Gamma=3$, standing for the three main players Vivint, SunRun and SolarCity), thereby altering the solution to $\mathcal{P}_{2}$. Our experiments compare the performance of the tariff structures utilized in the states of Nevada and New Mexico to the performance of our tariff $\mathcal{T}_{3}$, and to a theoretical first-best solution to $\mathcal{P}_{2}$. As we will see, while both states' tariffs are able to feasibly generate the outcome $\vec{z}^{*}$ specified by $\mathcal{P}_{1}$, they induce poor customer equity outcomes in problem $\mathcal{P}_{2}$. In contrast, our tariff achieves close to the first-best outcome. Our numerical results are qualitatively unaltered if we disallow net suppliers.

These solutions are based on the four tier customer model, which is estimated in Appendix A.5 by grouping households in the data set. As a robustness check, we compare the performance of these solutions on the full data set with 112 discrete household types. In all our experiments we find that our tariff produces a $\mathcal{P}_{1}$ objective and environmental welfare $\Delta_{W E}$ much closer to the target value than $\mathcal{T}_{1}$ and $\mathcal{T}_{2}$. Our tariff also leads to a better than targeted objective value for $\mathcal{P}_{2}$. In our experiments, $\mathcal{T}_{3}$ favors customers in preference to the utility, whereas $\mathcal{T}_{1}$ and $\mathcal{T}_{2}$ tend to favor the utility.

\footnotetext{
${ }^{4}$ We use the 2009 edition of the survey because the 2015 edition groups Nevada, New Mexico and Arizona together.
} 


\subsection{Comparison of tariff structures}

As noted in Section 4, not all customers who are financially incentivized to install solar do so; we attempt to capture this inertia by letting $\pi_{i}$ be the proportion of tier $i$ households that adopt solar if financially prudent. We estimate a reference level of $\pi_{i}$ for each tier using data from the U.S. Energy Information Administration's Residential Energy Consumption 2015 Survey (U.S. Energy Information Administration, 2015). Specifically, we use data from the Pacific Census Region, where households have had significant federal and state incentives to adopt solar (Borlick and Wood, 2014). We scale these $\pi_{i}$ values to reflect a target adoption scenario that we peg to Hawaii's, where $31 \%$ of single-family households were estimated to have installed rooftop solar as of 2018 (Feldman et al., 2018). Appendix A.8 shows the resulting $\pi_{i}$ levels. To study this situation with partial adoption within a tier, we reformulate $\mathcal{P}_{1}$ so that the $\Delta_{E}^{z}$ values accurately reflect the change in energy demanded from $U$ given adoption levels $\pi_{i}$. An analogous reformulated version of $\mathcal{P}_{2}$ is presented in Appendix A.6.

We now individually consider the cases of Nevada and New Mexico. Since the outcome of $\mathcal{P}_{1}$ critically depends on $c_{u}^{z_{i}}$, which in turn depends on which electricity sources are displaced by rooftop solar, we consider three different scenarios: (A) Rooftop solar displaces the most widely used source in the state; (B) Rooftop solar displaces all sources in proportion to the current energy mix in the state; and (C) Rooftop solar displaces sources in order of their levelized cost, i.e., first displaces the most expensive source, and then the next most expensive source and so on. For conciseness, we only present numerical results related to scenario (A). Our insights from scenarios (B) and (C) are similar, and we therefore relegate their results to Appendix B.5.

We solve problem $\mathcal{P}_{1}$ for each of these three scenarios. For each solution, we then evaluate eight sub-scenarios for $\mathcal{P}_{2}$ by choosing combinations of (i) $\Gamma$, the number of solar companies, from set $\{1,3\}$; (ii) $\Delta_{S}$, the solar industry profit, from the set $\left\{1,10^{6}\right\}$; and (iii) $\Delta_{C}$, the total financial welfare improvement of customers, from the set $\left\{1,10^{6}\right\}$. (Fixing $\Delta_{C}$ and $\Delta_{S}$ automatically fixes $\Delta_{U}$.) For each of these sub-scenarios, we solve $\mathcal{P}_{2}$ using the tariff structure in the state, and then using our suggested two-part tariff $\mathcal{T}_{3}$. We report the objective value of $\mathcal{P}_{2}$ that results from each of these experiments, and also report the theoretical first-best solution to $\mathcal{P}_{2}$. Since $\mathcal{P}_{2}$ 's objective is to minimize the maximum adverse financial impact to customers, the first-best tariff solution would divide $\Delta_{C}$ equally over all the households. 
Table 3 Nevada's Experiments for Scenario (A) - Rooftop Solar Replaces Natural Gas

\begin{tabular}{|c|c|c|c|c|c|c|c|}
\hline $\mathcal{P}_{1}$ & \multicolumn{7}{|c|}{$\mathcal{P}_{2}$} \\
\hline Adopting Tiers & \multicolumn{4}{|c|}{ Sub-Scenario Setting } & \multicolumn{3}{|c|}{$\mathcal{P}_{2}$ Objective Value $(\$)$} \\
\hline & $\begin{array}{c}\Gamma \\
(\$ \mathrm{MM})\end{array}$ & $\begin{array}{c}\Delta_{C} \\
(\$ \mathrm{MM})\end{array}$ & $\left(\begin{array}{l}\Delta_{S} \\
(\$ \mathbf{M M})\end{array}\right.$ & $\left(\begin{array}{l}\Delta_{U} \\
(\$ \mathrm{MM})\end{array}\right.$ & $\begin{array}{l}\text { NV } \\
\text { Tariff }\end{array}$ & $\begin{array}{l}\text { Our } \\
\text { Tariff }\end{array}$ & $\begin{array}{c}\text { First-Best } \\
\text { Tariff }\end{array}$ \\
\hline Objective Value (\$MM) & 1 & 0.00 & 0.00 & -41.30 & 10.9 & 0.0 & 0.0 \\
\hline 27.82 & 1 & 0.00 & 1.00 & -42.30 & 2.1 & 0.0 & 0.0 \\
\hline & 1 & 1.00 & 0.00 & -42.30 & 9.7 & -1.0 & -1.2 \\
\hline$\Delta_{W F}(\$ \mathbf{M M})$ & 1 & 1.00 & 1.00 & -43.30 & 0.9 & -0.9 & -1.2 \\
\hline-41.30 & 3 & 0.00 & 0.00 & -41.30 & 1.8 & 0.0 & 0.0 \\
\hline & 3 & 0.00 & 1.00 & -42.30 & 1.8 & 0.0 & 0.0 \\
\hline$\Delta_{W E}(\$ \mathbf{M M})$ & 3 & 1.00 & 0.00 & -42.30 & 0.6 & -0.9 & -1.2 \\
\hline 69.12 & 3 & 1.00 & 1.00 & -43.30 & 0.6 & -0.9 & -1.2 \\
\hline
\end{tabular}

Table 2 NV's Base-case Supply Mix

\begin{tabular}{lc}
\hline & Supply \% \\
\hline Natural Gas & 67.43 \\
Utility-Scale Solar & 11.90 \\
Biomass & 0.13 \\
Wind & 0.79 \\
Coal & 6.27 \\
Hydroelectric & 4.75 \\
Geothermal & 8.73 \\
\hline
\end{tabular}

5.1.1. Nevada Table 2 shows Nevada's electricity mix in the base case. The most widely used electricity source is natural gas; therefore this is the source that rooftop solar displaces under scenario (A). The optimal solution to $\mathcal{P}_{1}$ in this scenario is to induce all 4 tiers to adopt, resulting in an environmental welfare improvement of $\$ 69.12 \mathrm{MM}$ and a financial welfare loss of $\$ 41.30 \mathrm{MM}$.

The results of our experiments for scenario (A) are presented in Table 3. Recall that the objective value of $\mathcal{P}_{2}$ is the impact on the most adversely affected customer. As all the $\mathcal{P}_{2}$ values corresponding to $\mathcal{T}_{3}$ are non-positive, there is no cross-subsidization. Furthermore, these values are very close to the first-best solution. On the other hand, under Nevada's existing tariff:

- The objective is worse under the monopolistic solar case $(\Gamma=1)$ than the corresponding objective in the competitive solar case $(\Gamma=3)$, implying that Nevada's existing tariff is helped by competition in the solar marketplace.

- An increase of either $\Delta_{C}$ or $\Delta_{S}$ improves the objective: the objective is at its worst value when $\Delta_{C}$ and $\Delta_{S}$ are low (and all the financial surplus goes to the utility company). This also implies that taking $\Delta_{S}=0$ does not have the same effect as adding Cournot competition to the solar market (as Cournot competition improves the objective).

5.1.2. New Mexico New Mexico's net-metering regulations have also seen some recent opposition (Robert Walton, 2016). As it stands, New Mexico operates a tiered retail net-metering tariff that does not allow discrimination between solar and non-solar households (NC Clean Energy Technology Center, 2017), i.e., the tariff structure treated in Section 4.2. Recall that our estimates 
in Table 3 categorized customers in New Mexico into four tiers. We use $p_{r 0}=\$ 0.08822, \$ 0.09003$, $\$ 0.09705$, and $\$ 0.09858$ for the rates for tiers 1, 2, 3, and 4 respectively (PNM Energy, 2018). For the base case, we choose rate class boundaries in between the tier demand values $d_{i}$ : rate class 1 applies to customers who demand up to $9309 \mathrm{kWh}$, rate class 2 applies to customers who consume between 9309 and $11555.5 \mathrm{kWh}$, rate class 3 applies to customers who demand between 11555.5 and $13756.5 \mathrm{kWh}$, and rate class 4 applies to customers who demand more than $13756.5 \mathrm{kWh}$.

Now, we consider the modifications required to the tariff structure in the with-solar case. Recall that customer falling in rate class $c$ would, under this tariff structure have a utility bill of $r_{c} n+f$, where $n$ is the net demand of the customer. From the estimates of $d$ and $g$ in Table 3, we compute the net demand $(d-g)$ values for all tiers, if they were to adopt. A tier 1 customer who adopts has a net demand of $3031 \mathrm{kWh}$, a tier 2 customer who adopts has a net demand of $1482 \mathrm{kWh}$, a tier 3 customer who adopts has a net demand of $2356 \mathrm{kWh}$, and a tier 4 customer who adopts has a net demand of $-2001 \mathrm{kWh}$ (tier 4 customers are net suppliers). In order to give additional flexibility to New Mexico's tariff, we add a fifth rate class that applies to net demands of up to $5921 \mathrm{kWh}$. This fifth rate class will then apply to all households that adopt solar. ${ }^{5}$ The table in Appendix A.7 summarizes the rate classes under consideration.

We compare New Mexico's tiered tariff structure to a variant of our tariff structure $\mathcal{T}_{3}$, featuring a uniform fixed cost $f$ for all customers (adopters and non-adopters) across all tiers, and tierdependent variable costs $p_{r_{i}}$ that apply to tier $i$ adopters. A tier $i$ non-adopter faces the same variable cost $p_{r 0}$ that she would face in the base-case; we do this to accommodate the fact that $p_{r 0}$ varies by tier (see footnote 3 in Section 4.3). We also impose constraints to make rates $p_{r_{i}}, \forall i$ positive.

Table 4 NM's Base-case Supply Mix

\begin{tabular}{lc}
\hline & Supply \% \\
\hline Natural Gas & 35.65 \\
Utility-Scale Solar & 4.13 \\
Biomass & 0.06 \\
Wind & 18.64 \\
Coal & 41.02 \\
Hydroelectric & 0.46 \\
Geothermal & 0.04 \\
\hline
\end{tabular}

Table 4 shows New Mexico's electricity mix in the base case. The most widely used electricity source is coal; therefore this is the source that rooftop solar displaces under scenario (A). The optimal solution to $\mathcal{P}_{1}$ in this scenario is to induce all 4 tiers to adopt, resulting in an environmental welfare improvement of $\$ 157.51 \mathrm{MM}$ and a financial welfare loss of \$-4.15 MM. This solution to $\mathcal{P}_{1}$ has a much lower adverse financial impact than the corresponding solution for Nevada, because coal is both financially and environmentally more expensive than natural gas.

\footnotetext{
${ }^{5}$ Adding a new rate class for each net-demand usage level will implicitly enable the New Mexico tariff to distinguish
} between solar and non-solar customers, making it equivalent to our tariff. 
Table 5 New Mexico's Experiments for Scenario (A) - Rooftop Solar Replaces Coal

\begin{tabular}{|c|c|c|c|c|c|c|c|}
\hline $\mathcal{P}_{1}$ & \multicolumn{7}{|c|}{$\mathcal{P}_{2}$} \\
\hline Adopting Tiers & \multicolumn{4}{|c|}{ Sub-Scenario Setting } & \multicolumn{3}{|c|}{$\mathcal{P}_{2}$ Objective Value $(\$)$} \\
\hline & $\begin{array}{c}\Gamma \\
(\$ \mathrm{MM})\end{array}$ & $\begin{array}{c}\Delta_{C} \\
(\$ \mathrm{MM})\end{array}$ & $\begin{array}{c}\Delta_{S} \\
(\$ \mathrm{MM})\end{array}$ & $\begin{array}{ll} & \Delta_{U} \\
(\$ \mathrm{MM})\end{array}$ & $\begin{array}{l}\text { NM } \\
\text { Tariff }\end{array}$ & $\begin{array}{l}\text { Our } \\
\text { Tariff }\end{array}$ & $\begin{array}{c}\text { First-Best } \\
\text { Tariff }\end{array}$ \\
\hline Objective Value (\$MM) & 1 & 0.00 & 0.00 & -4.15 & 83.0 & 0.0 & 0.0 \\
\hline 153.26 & 1 & 0.00 & 1.00 & -5.15 & 76.8 & 0.0 & 0.0 \\
\hline & 1 & 1.00 & 0.00 & -5.15 & 81.4 & -1.6 & -1.6 \\
\hline$\Delta_{W F}(\$ \mathbf{M M})$ & 1 & 1.00 & 1.00 & -6.15 & 75.1 & -1.6 & -1.6 \\
\hline-4.15 & 3 & 0.00 & 0.00 & -4.15 & 55.4 & 0.0 & 0.0 \\
\hline & 3 & 0.00 & 1.00 & -5.15 & 39.4 & 0.0 & 0.0 \\
\hline$\Delta_{W E}(\$ \mathbf{M M})$ & 3 & 1.00 & 0.00 & -5.15 & 36.6 & -1.6 & -1.6 \\
\hline 157.51 & 3 & 1.00 & 1.00 & -6.15 & 48.3 & -1.6 & -1.6 \\
\hline
\end{tabular}

The results of our experiments for scenario (A) are presented in Table 5. The observations made for Nevada largely carry over to New Mexico's case. However, the specific objective values are significantly worse under New Mexico's tariff than under Nevada's tariff, suggesting that although the cross-subsidization effect is present in both cases, it is worse when the regulator is unable to discriminate between solar and non-solar customers.

In summary, although Proposition 1 showed that $\mathcal{P}_{2}$ might not be feasible under the non-tiered tariff structure (20), we did not encounter infeasibility in our experiments. However, while feasible, the non-tiered linear tariff structures in Nevada and the non-differentiating tariff in New Mexico performed poorly compared to our tiered tariff structure with respect to their ability to avoid CS.

5.1.3. Performance on 112 tier data set In Sections 5.1.1-5.1.2, we evaluated the performance of the tariff structures on a four tier simplification of household heterogeneity (most tiered tariff structures in the US have fewer than five tiers). We now evaluate how these tariffs perform, relative to their projected performance, when the actual number of distinct household types exceeds the number of tiers modeled. To do so, we compute the actual adoption outcomes and bill savings induced by these computed solutions on the full set of 112 distinct household types in our data, and present the results for Scenario (A) in Tables 6-7. The results for Scenarios (B) and (C) are in Appendix B.5, and closely mirror the results presented in Tables 6-7.

We first discuss the performance with respect to Problem $\mathcal{P}_{1}$. In all 48 experiments, all tariffs fall slightly short of the target objective, but our tariff comes closer to achieving $\mathcal{P}_{1}$ 's targeted objective than $N V^{\prime}$ 's and $N M$ 's tariffs. The extent of adoption under our tariff, and hence the environmental welfare, as implied by $\Delta_{W E}$, is also closer to the target adoption level than the states' tariffs in most experiments (with the exception of the eight Scenario (C) experiments for Nevada). 
Table 6 Nevada - 112-tier Performance for Scenario (A)

\begin{tabular}{|c|c|c|c|c|c|c|c|c|c|c|c|c|c|c|c|c|c|c|c|c|c|}
\hline \multirow[t]{2}{*}{$\Gamma$} & \multicolumn{3}{|c|}{$\begin{array}{c}\mathcal{P}_{1} \text { Objective } \\
(\$ \mathrm{MM})\end{array}$} & \multicolumn{3}{|c|}{$\begin{array}{c}\Delta_{W E} \\
(\$ \mathbf{M M})\end{array}$} & \multicolumn{3}{|c|}{$\begin{array}{c}\Delta_{W F} \\
(\$ \mathbf{M M})\end{array}$} & \multicolumn{12}{|c|}{$\mathcal{P}_{2}$ Objective } \\
\hline & $\begin{array}{l}\text { Tar- } \\
\text { get }\end{array}$ & $\begin{array}{c}\text { NV } \\
\text { Tariff }\end{array}$ & $\begin{array}{l}\text { Our } \\
\text { Tariff }\end{array}$ & $\begin{array}{l}\text { Tar- } \\
\text { get }\end{array}$ & $\begin{array}{l}\text { NV } \\
\text { Tariff }\end{array}$ & $\begin{array}{l}\text { Our } \\
\text { Tariff }\end{array}$ & $\begin{array}{l}\text { Tar- } \\
\text { get }\end{array}$ & $\begin{array}{c}\text { NV } \\
\text { Tariff }\end{array}$ & $\begin{array}{l}\text { Our } \\
\text { Tariff }\end{array}$ & $\begin{array}{l}\text { Tar- } \\
\text { get }\end{array}$ & $\begin{array}{c}\text { NV } \\
\text { Tariff }\end{array}$ & $\begin{array}{l}\text { Our } \\
\text { Tariff }\end{array}$ & $\begin{array}{l}\text { Tar- } \\
\text { get }\end{array}$ & $\begin{array}{c}\text { NV } \\
\text { Tariff }\end{array}$ & $\begin{array}{l}\text { Our } \\
\text { Tariff }\end{array}$ & $\begin{array}{l}\text { Tar- } \\
\text { get }\end{array}$ & $\begin{array}{c}\text { NV } \\
\text { Tariff }\end{array}$ & $\begin{array}{l}\text { Our } \\
\text { Tariff }\end{array}$ & $\begin{array}{l}\text { Tar- } \\
\text { get }\end{array}$ & $\begin{array}{c}\text { NV } \\
\text { Tariff }\end{array}$ & $\begin{array}{l}\text { Our } \\
\text { Tariff }\end{array}$ \\
\hline 1 & & 7.32 & 20.37 & & 19.70 & 51.16 & & -12.38 & -30.79 & 0.00 & 9.05 & 24.62 & 0.00 & -0.61 & -0.22 & -41.30 & -20.82 & -55.19 & 0.00 & 59.08 & 0.00 \\
\hline 1 & & 9.48 & 20.37 & & 24.89 & 51.16 & & -15.41 & -30.79 & 0.00 & 6.68 & 24.36 & 1.00 & -0.18 & 0.52 & -42.30 & -21.91 & -55.67 & 0.00 & 3.22 & 0.00 \\
\hline 1 & & 8.04 & 20.37 & & 21.45 & 51.16 & & -13.41 & -30.79 & 1.00 & 9.22 & 25.56 & 0.00 & -0.59 & -0.22 & -42.30 & -22.04 & -56.13 & -1.20 & 38.69 & -0.21 \\
\hline 1 & & 9.48 & 20.37 & & 24.89 & 51.16 & & -15.41 & -30.79 & 1.00 & 7.73 & 25.30 & 1.00 & -0.18 & 0.52 & -43.30 & -22.96 & -56.61 & -1.20 & 7.46 & -0.21 \\
\hline 3 & 27.82 & 9.48 & 20.37 & 69.12 & 24.89 & 51.16 & -41.30 & -15.41 & -30.79 & 0.00 & 6.70 & 24.62 & 0.00 & -0.54 & -0.22 & -41.30 & -21.57 & -55.19 & 0.00 & 1.81 & 0.00 \\
\hline 3 & & 9.48 & 20.37 & & 24.89 & 51.16 & & -15.41 & -30.79 & 0.00 & 6.63 & 24.36 & 1.00 & -0.18 & 0.52 & -42.30 & -21.86 & -55.67 & 0.00 & 1.79 & 0.00 \\
\hline 3 & & 9.48 & 20.37 & & 24.89 & 51.16 & & -15.41 & -30.79 & 1.00 & 7.70 & 25.56 & 0.00 & -0.54 & -0.22 & -42.30 & -22.57 & -56.13 & -1.20 & 0.61 & -0.21 \\
\hline 3 & & 9.48 & 20.37 & & 24.89 & 51.16 & & -15.41 & -30.79 & 1.00 & 7.63 & 25.30 & 1.00 & -0.18 & 0.52 & -43.30 & -22.86 & -56.61 & -1.20 & 0.59 & -0.21 \\
\hline
\end{tabular}

Table 7 New Mexico - 112-tier Performance for Scenario (A)

\begin{tabular}{|c|c|c|c|c|c|c|c|c|c|c|c|c|c|c|c|c|c|c|c|c|c|}
\hline \multirow[t]{2}{*}{$\Gamma$} & \multicolumn{3}{|c|}{$\begin{array}{c}P_{1} \text { Objective } \\
(\$ \mathrm{MM})\end{array}$} & \multicolumn{3}{|c|}{$\begin{array}{c}\mathcal{P}_{1} \\
\Delta_{W E} \\
(\$ \mathbf{M M})\end{array}$} & \multicolumn{3}{|c|}{$\begin{array}{c}\Delta_{W F} \\
(\$ \mathrm{MM})\end{array}$} & \multicolumn{3}{|c|}{$\begin{aligned} & \Delta_{C} \\
&(\$ \mathrm{MM})\end{aligned}$} & \multicolumn{3}{|c|}{$\begin{aligned} & \Delta_{S} \\
&(\$ \mathrm{MM})\end{aligned}$} & \multicolumn{3}{|l|}{$\mathrm{D}_{2}$} & \multicolumn{3}{|c|}{$\begin{array}{c}\mathcal{P}_{2} \text { Objective } \\
(\$)\end{array}$} \\
\hline & $\begin{array}{l}\text { Tar- } \\
\text { get }\end{array}$ & $\begin{array}{c}\text { NM } \\
\text { Tariff }\end{array}$ & $\begin{array}{l}\text { Our } \\
\text { Tariff }\end{array}$ & $\begin{array}{l}\text { Tar- } \\
\text { get }\end{array}$ & $\begin{array}{c}\text { NM } \\
\text { Tariff }\end{array}$ & $\begin{array}{l}\text { Our } \\
\text { Tariff }\end{array}$ & $\begin{array}{l}\text { Tar- } \\
\text { get }\end{array}$ & $\begin{array}{c}\text { NM } \\
\text { Tariff }\end{array}$ & $\begin{array}{l}\text { Our } \\
\text { Tariff }\end{array}$ & $\begin{array}{l}\text { Tar- } \\
\text { get }\end{array}$ & $\begin{array}{l}\text { NM } \\
\text { Tariff }\end{array}$ & $\begin{array}{l}\text { Our } \\
\text { Tariff }\end{array}$ & $\begin{array}{l}\text { Tar- } \\
\text { get }\end{array}$ & $\begin{array}{c}\text { NM } \\
\text { Tariff }\end{array}$ & $\begin{array}{l}\text { Our } \\
\text { Tariff }\end{array}$ & $\begin{array}{l}\text { Tar- } \\
\text { get }\end{array}$ & $\begin{array}{l}\text { NM } \\
\text { Tariff }\end{array}$ & $\begin{array}{l}\text { Our } \\
\text { Tariff }\end{array}$ & $\begin{array}{l}\text { Tar- } \\
\text { get }\end{array}$ & $\begin{array}{c}\text { NM } \\
\text { Tariff }\end{array}$ & $\begin{array}{c}\text { Our } \\
\text { Tariff }\end{array}$ \\
\hline 1 & & 44.83 & 137.99 & & 46.47 & 141.79 & & -1.64 & -3.80 & 0.00 & 15.69 & 211.33 & 0.00 & -0.41 & -0.06 & -4.15 & -16.92 & -215.07 & 0.00 & 263.92 & 0.00 \\
\hline 1 & & 44.83 & 137.99 & & 46.47 & 141.79 & & -1.64 & -3.80 & 0.00 & 15.24 & 208.13 & 1.00 & -0.12 & 0.84 & -5.15 & -16.76 & -212.77 & 0.00 & 253.46 & 0.00 \\
\hline 1 & & 44.83 & 137.99 & & 46.47 & 141.79 & & -1.64 & -3.80 & 1.00 & 16.69 & 212.33 & 0.00 & -0.41 & -0.06 & -5.15 & -17.92 & -216.07 & -1.60 & 262.28 & -1.63 \\
\hline 1 & & 44.83 & 137.99 & & 46.47 & 141.79 & & -1.64 & -3.80 & 1.00 & 16.24 & 209.13 & 1.00 & -0.12 & 0.84 & -6.15 & -17.76 & -213.77 & -1.60 & 251.83 & -1.63 \\
\hline 3 & 153.26 & 53.24 & 137.99 & 157.41 & 55.08 & 141.79 & -4.15 & -1.84 & -3.80 & 0.00 & 27.41 & 211.33 & 0.00 & -0.38 & -0.06 & -4.15 & -28.87 & -215.07 & 0.00 & 217.40 & 0.00 \\
\hline 3 & & 53.25 & 137.99 & & 55.08 & 141.79 & & -1.83 & -3.80 & 0.00 & 24.74 & 208.13 & 1.00 & -0.03 & 0.84 & -5.15 & -26.54 & -212.77 & 0.00 & 217.55 & 0.00 \\
\hline 3 & & 62.61 & 137.99 & & 64.67 & 141.79 & & -2.06 & -3.80 & 1.00 & 15.66 & 212.33 & 0.00 & -0.35 & -0.06 & -5.15 & -17.37 & -216.07 & -1.60 & 223.77 & -1.63 \\
\hline 3 & & 62.61 & 137.99 & & 64.67 & 141.79 & & -2.06 & -3.80 & 1.00 & 9.57 & 209.13 & 1.00 & 0.06 & 0.84 & -6.15 & -11.69 & -213.77 & -1.60 & 223.96 & -1.63 \\
\hline
\end{tabular}


The performance on $\mathcal{P}_{2}$ is more nuanced: First, all tariffs fall slightly short of the target solar profit $\Delta_{S}$, but our tariff comes closer to the target in all 48 experiments. Second, the value of $\Delta_{C}$, under both the states' tariffs and our tariffs, is higher than the target for all experiments. However, this does not translate to benefit for all customers under $N V$ 's and $N M$ 's tariffs (while it does under our tariff): $\mathcal{P}_{2}$ 's objective value is significantly higher (implying a higher worst-case loss) under the states' tariffs than under ours in all experiments. Our experiments show that there may be situations (like in New Mexico) when a four-tier tariff experiences some difficulty with respect to utility outcomes when applied to the entire set of 112 tiers. In this case our experiments show both NM's tariff and our tariff making a choice to sacrifice the utility's profit to the consumers. (This effect is more pronounced in the case of our tariff.) It is conceivable that to strike a better balance one might need a tariff with a greater number of tiers. We defer this exploration of the trade-off between fidelity (more tiers) and ease of application (fewer tiers) to future work.

\section{Conclusions and Future Work}

We show analytically that a tariff structure must be able to discriminate between customer tiers and between solar and non-solar customers to achieve societal objectives while also safeguarding customer equity. We present a simple implementation of such a tariff that corresponds to a buy-all, sell-all tariff; this implementation requires the regulator to set only three parameters: one retail rate and two buy-back rates. Thus regulators must migrate to tiered tariff structures and put solar and non-solar customers on different rate schedules in order to induce socially optimal outcomes, and furthermore, this migration is not necessarily difficult to implement. While states such as Arizona already have such tariffs, most utility tariffs in the U.S. do not have both these features.

Our recommended tariff structure addresses our chosen objective of minimizing crosssubsidization. For states that have fairness concerns around differentiating between customer tiers or between solar and non-solar customers, a different objective, and hence tariff structure, may be appropriate. This is a potential avenue for future research.

Our findings are robust to various extensions, including a competitive solar market-place and customers' electricity demand being elastic to price. Our work lays the foundation for several additional extensions. For instance, our model considers a flat-rate pricing scheme, rather than a time-of-use (TOU) pricing scheme such as the one being rolled out in California. Our model also assumes that any excess exported to the grid is compensated at the same rate. Some utilities (for example, PG\&E and Southern California Edison) compensate annual excess beyond the customer's annual grid usage at a lower rate. This is also a possible avenue for future work. Additionally, our model implicitly captures the impact of utility capacity investments in response to solar adoption 
through $c_{u}^{z}$ and $m_{u}^{z}$; an extension could treat these decisions as explicit outputs of the model. On the customer side, one could modify the assumption that all customers (or an exogenously defined proportion) who are incentivized to adopt solar do so. An interesting extension would be to endogenously determine the proportion of customers in a tier that would adopt as a function of savings generated. It would also be interesting to explore the trade-off between tariff implementability (few tiers) and accuracy (many tiers).

While this work explores a static setting, related questions can be explored in a dynamic setting, complementing literature such as Babich et al. (2020) and Lobel and Perakis (2011). Such work would require a significantly different model that captures the diffusion of solar among customers, the interaction between solar adoption penetration and solar cost, and utility capacity investment decisions. If such work also continued to capture heterogeneity in the customer base, this would necessitate more nuanced modeling of the regulator's optimization problem.

\section{References}

Aflaki S, Netessine S (2016) Strategic Investment in Renewable Energy Sources: The Effect of Supply Intermittency.

Agarwal A, Cai D, Shah S, Chandy M, Sherick R (2015) A Model for Residential Adoption of Photovoltaic Systems. 2015 IEEE Power $\&$ Energy Society General Meeting, 1-5 (IEEE).

Agrawal V, Toktay LB, Yucel S (2019) Non-Ownership Business Models for Solar Energy. Available at SSRN.

Al-Gwaiz M, Chao X, Wu OQ (2016) Understanding How Generation Flexibility and Renewable Energy Affect Power Market Competition. Manufacturing \& Service Operations Management.

Alizamir S, de Véricourt F, Sun P (2016) Efficient Feed-in-Tariff Policies for Renewable Energy Technologies. Operations Research, 64(1):52-66.

APS Energy (2019) Available Service Plans (APS Energy), URL https://www.aps.com/en/Residential/ Service-Plans/Compare-Service-Plans.

Aznar AY, Zinaman OR (2017) Grid-Connected Distributed Generation: Compensation Mechanism Basics. Technical report, National Renewable Energy Laboratory (NREL), Golden, CO (United States) OSTI Releasing Official.

Babich V, Lobel R, Yücel Ş (2020) Promoting solar panel investments: Feed-in-tariff vs. tax-rebate policies. Manufacturing $\&$ Service Operations Management.

Bauner C, Crago CL (2015) Adoption of Residential Solar Power Under Uncertainty: Implications for Renewable Energy Incentives. Energy Policy, 86:27-35.

Bird L, McLaren J, Heeter J, Linvill C, Shenot J, Sedano R, Migden-Ostrander J (2013) Regulatory Considerations Associated with the Expanded Adoption of Distributed Solar.

Blackburn G, Magee C, Rai V (2014) Solar Valuation and the Modern Utility's Expansion into Distributed Generation. The Electricity Journal, 27(1):18-32.

Bollinger B, Gillingham K (2012) Peer Effects in the Diffusion of Solar Photovoltaic Panels. Marketing Science, 31(6):900-912.

Borlick R, Wood L (2014) Net Energy Metering: Subsidy Issues and Regulatory Solutions. Issue Brief September.

Brown A, Bunyan J (2014) Valuation of Distributed Solar: A Qualitative View. The Electricity Journal, 27(10):27-48. 
Brown DP, Sappington D, et al. (2017) Designing Compensation for Distributed Solar Generation: Is Net Metering Ever Optimal? Energy Journal, 38(3):1-32.

Buhayar N (2016) Who Owns The Sun? (Bloomberg Business), URL http://www.bloomberg.com/features/ 2016-solar-power-buffett-vs-musk/.

Cai DW, Adlakha S, Low SH, De Martini P, Chandy KM (2013) Impact of Residential PV Adoption on Retail Electricity Rates. Energy Policy, 62:830-843.

California Public Utilities Commission (2020) California Public Utilities Commission (California Public Utilities Commission), URL http://www.cpuc.ca.gov/.

Chediak M, Buhayar N (2015) Buffett's Utility Wins as Sun Sets on Nevada Home Solar Subsidy (Bloomberg Business), URL https://www.bloomberg.com/news/articles/2015-12-21/ buffett-s-utility-wins-as-sun-sets-on-nevada-home-solar-subsidy.

Choudhary V, Ghose A, Mukhopadhyay T, Rajan U (2005) Personalized Pricing and Quality Differentiation. Management Science, 51(7):1120-1130.

Costello KW, Hemphill RC (2014) Electric Utilities Death Spiral: Hyperbole or Reality? The Electricity Journal, 27(10):7-26.

Darghouth NR, Barbose G, Wiser R (2011) The Impact of Rate Design and Net Metering on the Bill Savings from Distributed PV for Residential Customers in California. Energy Policy, 39(9):5243-5253.

Darghouth NR, Wiser RH, Barbose G, Mills AD (2016) Net Metering and Market Feedback Loops: Exploring the Impact of Retail Rate Design on Distributed PV Deployment. Applied Energy, 162:713-722.

Denholm P, Margolis RM, Drury E (2009) The Solar Deployment System (SolarDS) Model: Documentation and Sample Results (National Renewable Energy Laboratory).

Drury E, Denholm P, Margolis R (2013) Sensitivity of Rooftop PV Projections in the SunShot Vision Study to Market Assumptions. Contract, 303:275-3000.

Electricity Local (2019) United States Map of Electricity Deregulation (Electricity Local), URL https://www. electricitylocal.com/resources/deregulation/.

Feldman DJ, Margolis RM, Hoskins J (2018) Q4 2017/Q1 2018 Solar Industry Update. Technical report, National Renewable Energy Lab. (NREL), Golden, CO (United States).

Flores-Espino F (2015) Compensation for Distributed Solar: A Survey of Options to Preserve Stakeholder Value. National Renewable Energy Laboratory, Tech. Rep. NREL/TP-6A20, 62371.

Gagnon P, Sigrin B (2015) Distributed PV Adoption in Maine through 2021. Technical report, National Renewable Energy Laboratory (NREL), Golden, CO (United States).

Goodarzi S, Aflaki S, Masini A (2019) Optimal Feed-In Tariff Policies: The Impact of Market Structure and Technology Characteristics. Production and Operations Management, 28(5):1108-1128.

Google (2020) Google Project Sunroof (Google), URL https://www.google.com/get/sunroof\#p=0.

Hu S, Souza GC, Ferguson ME, Wang W (2015) Capacity Investment in Renewable Energy Technology with Supply Intermittency: Data Granularity Matters! Manufacturing \& Service Operations Management, 17(4):480-494.

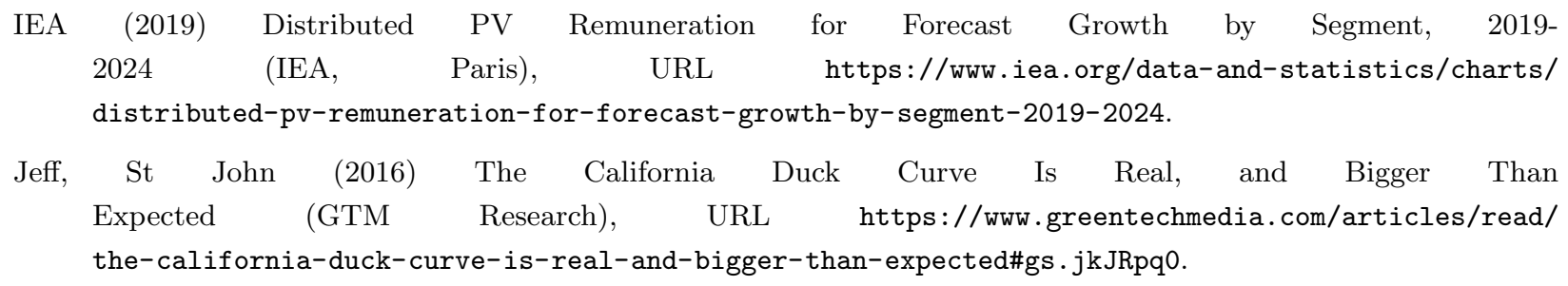


Singh, Scheller-Wolf: That's Not Fair: Tariff Structures for Electric Utilities with Rooftop Solar

Kari Lyderson (2017) Indiana Energy Bill Would Eliminate Net Metering, Move To Buy-All, SellAll Solar Model (Midwest Energy News), URL http://midwestenergynews.com/2017/01/24/ indiana-energy-bill-would-eliminate-net-metering-move-to-buy-all-sell-all-solar-model/.

Keyes J, Rábago K (2013) A Regulators Guidebook: Calculating the Benefits and Costs of Distributed Solar Generation. Latham, NY: Interstate Renewable Energy Council.

Kok G, Shang K, Yucel S (2015) Impact of Electricity Pricing Policies on Renewable Energy Investments and Carbon Emissions.

Krysti Shallenberger (2017a) Is Rooftop Solar Just a Toy for the Wealthy? (Utility Dive), URL https://www . utilitydive.com/news/is-rooftop-solar-just-a-toy-for-the-wealthy/441373/.

Krysti Shallenberger (2017b) Maine Lawmakers Fail to Override Governor's Veto of Solar Bill (Utility Dive), URL https://www.utilitydive.com/news/ maine-lawmakers-fail-to-override-governors-veto-of-solar-bill/448550/.

Lehr RL (2013) New Utility Business Models: Utility and Regulatory Models for the Modern Era. The Electricity Journal, 26(8):35-53.

Linvill C, Shenot J, Lazar J (2013) Designing Distributed Generation Tariffs Well. Montpelier, VT: Regulatory Assistance Project.

Lobel R, Perakis G (2011) Consumer Choice Model for Forecasting Demand and Designing Incentives for Solar Technology.

Lowder T, Zhou E, Tian T (2017) Evolving Distributed Generation Support Mechanisms: Case Studies from United States, Germany, United Kingdom, and Australia. Technical report, National Renewable Energy Lab.(NREL), Golden, CO (United States).

Meyers G (2015) SolarCity Accounts for $1 / 3$ of U.S. Residential Rooftop Installations in 2015 (CleanTechnica), URL https://cleantechnica.com/2015/12/29/ solarcity-accounts-for-13-of-us-residential-rooftop-installations-in-2015/.

Mike Munsell (2017) US Solar Market Grows 95\% in 2016, Smashes Records (GTM Research), URL https://www . greentechmedia.com/articles/read/us-solar-market-grows-95-in-2016-smashes-records\#gs.qK=_kE4.

Moore J, Keen J, Apt J (2016) The Sustainability of Net Metering. Electric Markets Research Foundation.

NC Clean Energy Technology Center (2017) Net Metering Program Overview (NC Clean Energy Technology Center), URL http://programs.dsireusa.org/system/program/detail/284.

NC Clean Energy Technology Center (2019) Net Metering Program Overview (NC Clean Energy Technology Center), URL http://programs.dsireusa.org/system/program/detail/42.

NC Clean Energy Technology Center, Meister Consultants Group (2019) The 50 States of Solar.

Office of Energy Efficiency \& Renewable Energy (2020) Residential and Commercial ITC Factsheets (Office of Energy Efficiency \& Renewable Energy), URL https://www.energy.gov/eere/solar/downloads/ residential-and-commercial-itc-factsheets.

Ong S, Denholm P, Doris E (2010) The Impacts of Commercial Electric Utility Rate Structure Elements on the Economics of Photovoltaic Systems (National Renewable Energy Laboratory).

PNM Energy (2018) Rates (PNM Energy), URL https://www.pnm.com/rates.

Pyper J (2016) Nevada Regulators Restore Retail-Rate Net Metering in Sierra Pacific Territory (Greentech Media), URL https://ww.greentechmedia.com/articles/read/ nevada-regulators-retore-retail-rate-net-metering-in-sierra-pacific-territo. 
Rai V, Sigrin B (2013) Diffusion of Environmentally-Friendly Energy Technologies: Buy Versus Lease Differences in Residential PV Markets. Environmental Research Letters, 8(1):014022.

Rawls J (1974) Some reasons for the maximin criterion. The American Economic Review, 64(2):141-146.

Reisinger D (2019) Why Tesla Slashed Its Solar Panel Prices (Fortune), URL https://fortune.com/2019/05/02/ tesla-solar-panels-price-cut/.

Reiss PC, White MW (2005) Household Electricity Demand, Revisited. The Review of Economic Studies, 72(3):853883.

Ritzenhofen I, Birge JR, Spinler S (2016) The Structural Impact of Renewable Portfolio Standards and Feed-in Tariffs on Electricity Markets. European Journal of Operational Research, 255(1):224-242.

Robert Walton (2016) New Mexico Settlement Blocks Solar Fees Proposed by Xcel Energy (Utility Dive), URL https: //www.utilitydive.com/news/new-mexico-settlement-blocks-solar-fees-proposed-by-xcel-energy/ $424357 /$.

Satchwell A, Mills A, Barbose G (2015) Quantifying the Financial Impacts of Net-Metered PV on Utilities and Ratepayers. Energy Policy, 80:133-144.

Shahan Z (2016) Cost Of Solar Systems From SolarCity vs Sunrun \& Vivint Solar, and Cost Per Watt Of Solar Sales/Acquisition (Clean Technica), URL https://cleantechnica.com/2016/07/19/ cost-solarcity-solar-systems-vs-sunrun-vivint-solar-cost-per-watt-solar-salesacquisition/.

State of Connecticut Public Utilities Commission (2018) Substitute Senate Bill No. 9 (State of Connecticut Public Utilities Commission), URL https://www.cga.ct.gov/2018/act/pa/pdf/2018PA-00050-R00SB-00009-PA . pdf.

State of Maine (2019) Governor Mills Signs Legislation to Restore Net Metering \& Incentivize Growth of Solar Power in Maine (State of Maine Office of Governor Janet T. Mills), URL https://www.maine.gov/governor/mills/news/ governor-mills-signs-legislation-restore-net-metering-incentivize-growth-solar-power-maine.

State of Maine Public Utilities Commission (2017) Amendments to Net Energy Billing Rule (State of Maine Public Utilities Commission), URL https://www.insourcerenewables.com/sites/default/files/ $993 e 4 a c c-029 b-4 e a 4-a 38 a-885 d e c 26 e 0 c c-1 . p d f$.

Sunar N, Birge JR (2018) Strategic Commitment to a Production Schedule with Uncertain Supply and Demand: Renewable Energy in Day-Ahead Electricity Markets. Management Science.

Sunar N, Swaminathan JM (2018) Net-Metered Distributed Renewable Energy: A Peril for Utilities? Kenan Institute of Private Enterprise Research Paper, (18-24).

Sundararajan A (2004) Nonlinear Pricing of Information Goods. Management Science, 50(12):1660-1673.

SunRun (2019) Power Purchase Agreement (PPA) (SunRun), URL https://www.sunrun.com/go-solar-center/ solar-terms/definition/power-purchase-agreement.

US Energy Information Administration (2009) 2009 RECS Survey Data (EIA), URL https://www.eia.gov/ consumption/residential/data/2009/.

US Energy Information Administration (2015) 2015 RECS Survey Data (EIA), URL https://www.eia.gov/ consumption/residential/data/2015/.

Varian HR (1989) Price discrimination. Handbook of Industrial Organization, 1:597-654.

Wu OQ, Kapuscinski R (2013) Curtailing Intermittent Generation in Electrical Systems. Manufacturing \& Service Operations Management, 15(4):578-595.

Zhou Y, Scheller-Wolf AA, Secomandi N, Smith S (2014) Managing Wind-Based Electricity Generation in the Presence of Storage and Transmission Capacity. 


\section{That's Not Fair: Tariff Structures for Electric Utilities with Rooftop Solar Supporting Material}

\section{A.1 Proofs}

\section{A.1.1 Proof by Counter-Example for Proposition 1}

We prove Proposition 1 by showing the following counter-example with three tierses of customers. Under this tariff structure, we have $t(i)=\frac{d_{i} r_{d}+r_{0}-\left(\left(d_{i}+e_{i}-g_{i}\right) s_{d}+e_{i} s_{e}+s_{0}\right)}{g_{i}}$. Let $\vec{z}^{*}$ specify that tiers 2 and 3 adopt and class 1 does not adopt. Let $h_{1}=4000, h_{2}=250, h_{3}=1000, d_{1}=1000, d_{2}=2000, d_{3}=3000, g_{1}=500, g_{2}=$ $1000, g_{3}=1500, e_{1}=200, e_{2}=400, e_{3}=600$. Let $c_{s}^{z}=c_{s}, \forall \vec{z}$. $R$ can choose between two possible orderings: Under ordering $o_{1}, t(1)<t(2) \leq t(3)$, and $m\left(o_{1}\right)$ is 2 , while under ordering $o_{2}, t(1)<t(3) \leq t(2)$, and $m\left(o_{2}\right)$ is 3. It is straightforward to show infeasibility under both these orderings. Interested readers may refer to the details presented in Appendix B.3.

\section{A.1.2 Proof of Proposition 2}

To prove this property, we choose a number $\epsilon>0$ and consider a net-metering tariff system (where customers pay a variable charge proportional to their net energy usage). We choose the ordering $t(i) \leq t(j), \forall i<j, j \neq$ $m$ and $t(m-1)<t(m)$, which is consistent with tiers $m, m+1, \ldots, I$ being adopters. Setting $r_{d}=s_{d}$, $s_{e}=-s_{d}$, and $r_{0}=s_{0}-\epsilon$, the ordering constraints $t(i) \leq t(j)$ simplify to $s_{d}-\frac{\epsilon}{g_{i}}<s_{d}-\frac{\epsilon}{g_{j}}$, which is true, because $g_{i}<g_{j}$. This leaves us with a linear system of the form $A x=b$ with five unknowns: $r_{d}, s_{d}, s_{e}, r_{0}$, and $s_{0}$. Since the rows of $A$ are linearly independent, $\mathcal{P}_{2}$ is feasible under this ordering.

\section{A.1.3 Proof of Proposition 3}

This proof proceeds in two parts. In the first part, we will show that ignoring the set of equations (15) and (16), we can always find a set of $t(i)$ values that satisfy (17)-(19). In the second part, we will show that corresponding to the set of $t(i)$ values found, we can find $r_{c}, \forall c \in C$ that satisfy (15) and (16) .

Part 1: First, re-index the usage tiers so the index matches the ordering $o$. Note that after re-ordering, we no longer have that $g_{i} \leq g_{i+1} \forall i \in\{1,2, \ldots, I-1\}$. Now, observe that (17) can be rewritten as $t(i) \leq$ $t(i+1), \forall i \in\{1,2, \ldots, I-1\}-m(o)$ and $t(m(o)-1)<t(m(o))$. Equation (18) can be rewritten as $\left(t(m(o))-c_{s}\right) \sum_{i=m(o)}^{I} h_{i} g_{i}=\Delta_{S}$ and constraints $(19)$ can be rewritten as $\left(t(m(o))-c_{s}^{z^{*}}\right) \sum_{i=m(o)}^{I} h_{i} g_{i}=\Delta_{S}$ and constraints (19) can be rewritten as $\left(t(i)-c_{s}^{z_{i}}\right) \sum_{j=i}^{I} h_{j} g_{j}<\Delta_{S} \forall t(i) \neq t(m(o))$. With some manipulation, we obtain:

$$
\begin{aligned}
& t(i)<t(i+1) \forall i \in\{1,2, \ldots, I-1\} \\
& t(m(o))=c_{s}^{z^{*}}+\frac{\Delta_{S}}{\sum_{i=m(o)}^{I} h_{i} g_{i}} \\
& t(i)<c_{s}^{z_{i}}+\frac{\Delta_{S}}{\sum_{j=i}^{I} h_{j} g_{j}}, \forall t(i) \neq t(m(o))
\end{aligned}
$$

Inequalities (29) provide upper bounds on all the $t(i)$ values, and (28) pins down the value of $t(m(o))$. Notice that these upper bounds are increasing in $i$, because $\Delta_{S}>0, \sum_{j=i}^{I} h_{j} g_{j}$ is decreasing in $i$ and $c_{s}^{z_{i}}$ is increasing in $i$. Therefore, $\exists t(i) \forall i \in\{1,2, \ldots, I-1\}$ that respect (27) and the specified upper bounds. 
Part 2: Once a set of values $t(i)$ is found, we need to map them to rate class tariffs $r_{c}$. We begin by transforming the tariff structure $\mathcal{T}_{2}$ to include a fixed cost $f$, i.e., $T\left(d^{\prime}, e, s\right)=r_{c}^{\prime}\left(d^{\prime}-e\right)+f$, where $c$ is the rate class corresponding to net demand level $d^{\prime}-e$. Note that the original $r_{c}$ values can be recovered from the transformed $r_{c}^{\prime}$ values such that the tariff $T\left(d^{\prime}, e, s\right)$ is unchanged: $r_{c}=r_{c}^{\prime}+\frac{f}{d^{\prime}-e}$. Next, we examine the set of equations (15) under this transformed tariff. Each of these $I$ equations takes the form:

$$
t(i)=\frac{r_{m}^{\prime} d_{i}+f-\left(r_{n}^{\prime}\left(d_{i}-g_{i}\right)+f\right)}{g_{i}}=r_{m}^{\prime}\left(\frac{d_{i}}{g_{i}}\right)+r_{n}^{\prime}\left(\frac{d_{i}-g_{i}}{g_{i}}\right),
$$

where $m$ is the rate class corresponding to net usage level $d_{i}$, and $n$ is the rate class corresponding to net usage level $d_{i}-g_{i}$. Taken together, these $I$ equations constitute an under-determined linear system of the form $A \overrightarrow{r^{\prime}}=\vec{t}$, where $r^{\prime}$ is a $|C|$ dimensional vector of $r_{c}$ values, $\vec{t}$ is an $I$ dimensional vector of $t(i)$ values, and $A$ is a matrix with $I$ rows and $|C|>I$ columns. If the rows of $A$ are linearly independent, then the system has an infinite number of solutions. For the sake of contradiction, assume that the rows are linearly dependent. Then, there must exist an $I$ dimensional vector $\vec{\lambda} \neq \overrightarrow{0}_{I \times 1}$ such that $\vec{\lambda}^{T} A=\overrightarrow{0}_{1 \times|C|}$. Let $m_{1}=\operatorname{argmax} d_{i}$. Let $c_{1}$ be the column in $A$ corresponding to the rate class into which a tier $m_{1}$ customer would fall if they did not adopt solar. This column has exactly one non-zero entry because no other household can fall into this rate class, whether they adopt solar or not. Let $w_{1}$ be the index of the row in $A$ that contains this non-zero entry. Then, it must be that the $w_{1}^{t h}$ entry of $\vec{\lambda}$ is 0 in order for the $c_{1}^{t h}$ entry of $\vec{\lambda}^{T} A$ to be 0 . Therefore, the vector $\vec{\lambda}^{T} A$ is unaltered if we replace all entries in the $w_{1}^{\text {th }}$ row of $A$ by zero. Now, this same argument can be applied repeatedly to assert that all other entries of $\vec{\lambda}$ must also be zero: choose $m_{2}=\underset{i \neq m_{1}}{\operatorname{argmax}} d_{i}$, find the index $c_{2}$ of the column corresponding to the rate class to which a tier $m_{2}$ customer would belong if it did not adopt solar, and observe that exactly one row corresponding to this column now has a non-zero entry (recall that we changed all entries in row $w_{1}$ to 0 ). Let $w_{2}$ be the index of this row. We can assert that the $w_{2}^{\text {th }}$ entry of $\vec{\lambda}=0$. By repeating this procedure, we can assert that all entries of $\vec{\lambda}$ are 0 . This contradicts our assumption, and therefore, the rows of $A$ are linearly independent. Therefore, we can obtain values of $r_{c}^{\prime}$ consistent with the equations (30). These values can then be substituted in (16) to find a feasible $f$. Now, we use the transformation $r_{c}=r_{c}^{\prime}+\frac{f}{d^{\prime}-e}$ to find the equivalent un-transformed tariff parameters $r_{c}$. Note that since (30) is independent of $f$, it continues to hold when we replace $r_{c}^{\prime}$ by $r_{c}$. Further, since the tariffs $T\left(d^{\prime}, e, f\right)$ are invariant under this transformation, the utility payments, and hence (16), are unchanged.

\section{A.1.4 Proof by Counter-Example for Proposition 4}

We prove Proposition 4 by showing the following counter-example with three tiers of customers. Let $h_{1}=$ $445, h_{2}=218, h_{3}=1000, d_{1}=500, d_{2}=681, d_{3}=1024, g_{1}=100, g_{2}=181, g_{3}=343, p_{r 0}=0.1, \Delta_{S}=1, c_{s}^{z}=$ $3 / 40, \forall z$. With these parameters, there are four possible values of net demand for a household:

1. Tier 1 household adopts: Net demand $=d_{1}-g_{1}=400$.

2. Tier 1 household does not adopt, or tier 2 household adopts: Net Demand $=d_{1}=d_{2}-g_{2}=500$.

3. Tier 2 household does not adopt, or tier 3 household adopts: Net Demand $=d_{2}=d_{3}-g_{3}=681$.

4. Tier 3 household does not adopt: Net Demand $=d_{3}=1024$.

Therefore, $U$ 's rate schedule must specify 4 different rate classes that apply at each of these net demand levels. Let the rates corresponding to these rate class levels be $r_{1}, r_{2}, r_{3}$, and $r_{4}$ respectively. To make this concrete, let rate $r_{1}$ apply to net-demand levels $0-450 \mathrm{kWh}, r_{2}$ apply to net-demand levels $450-550 \mathrm{kWh}, r_{3}$ apply to net-demand levels $550-850 \mathrm{kWh}$ and $r_{4}$ apply to net-demand levels larger than $850 \mathrm{kWh}$.

$$
t(1)=r_{1}+\left(r_{2}-r_{1}\right) \frac{d_{1}}{g_{1}} ; t(2)=r_{2}+\left(r_{3}-r_{2}\right) \frac{d_{2}}{g_{2}} ; t(3)=r_{3}+\left(r_{4}-r_{3}\right) \frac{d_{3}}{g_{3}}
$$

Let $\Delta_{U}$ be chosen so that $\Delta_{C}=0$. Therefore, customers as a whole gain exactly 0 . It is now straightforward to show that customer tiers 1,2 , and 3 cannot all be financially worse off by an amount arbitrarily close to 0 after solar adoption. Interested readers may refer to Appendix B.4 for details. Therefore, this tariff structure does not allow $R$ to induce a CS-free outcome. 


\section{A.1.5 Proof of Proposition 5}

Part (a): We show this constructively. First, observe that under this tariff structure, equation (15) simplifies to $t(i)=p_{r}-f_{i} / g_{i}, \forall i$. Now, observe that this schedule of fixed costs respects the ordering that the $t(i)$ values are required to have, because $c_{s}^{z_{A l l}} \leq c_{s}^{z^{*}}<t(m)$. Further, the IC constraints are respected: setting a solar price of $t(i)=c_{s}^{z_{A l l}}, i<m$ brings $S$ non-positive profit (because $c_{s}^{z_{A l l}} \leq c_{s}^{z_{i}}, \forall i$ ), and since $t(i)=t(j), \forall i, j \geq m$, the IC constraints naturally hold.

Part (b): We begin by proving Lemma 1, which is useful in examining the properties of $T^{*}$.

Lemma 1. Consider an adopting tier $i$ under tariff structure (21). We have $g_{i} p_{r}-g_{i} p_{s}-f_{i} \geq 0$.

Proof: We have that $p_{s}=t(m)=p_{r}-\frac{f_{m}}{g_{m}}$. For all adopting tiers $i, t(m) \leq t(i) \Leftrightarrow \frac{f_{m}}{g_{m}} \geq \frac{f_{i}}{g_{i}}$ (from (15)). Therefore, $g_{i} p_{r}-g_{i} p_{s}-f_{i}=g_{i} p_{r}-g_{i}\left(p_{r}-\frac{f_{m}}{g_{m}}\right)-f_{i}=g_{i} \frac{f_{m}}{g_{m}}-f_{i} \geq 0$.

Now, to demonstrate the ability of tariff $T^{*}$ to induce CS-free outcomes, let us examine what happens to the cash outflow of every tier under this schedule of rates. For a non-adopting tier $i<m$, the decrease in cash outflow (and therefore benefit to a customer in the tier) is $\left(p_{r 0}-p_{r}\right) d_{i}$. For an adopting tier, the decrease in cash outflow is $p_{r 0} d_{i}-\left(p_{r}\left(d_{i}-g_{i}\right)+f_{i}+p_{s} g_{i}\right)=\left(p_{r 0}-p_{r}\right) d_{i}+p_{r} g_{i}-f_{i}-p_{s} g_{i} \geq\left(p_{r 0}-p_{r}\right) d_{i}$ from Lemma 1.

Accordingly, it is sufficient for us to now show that $p_{r} \leq p_{r 0}$ under this schedule when $\Delta_{C} \geq 0$. We have $\Delta_{C}=\sum_{1}^{I} h_{i}\left(p_{r 0}-p_{r}\right) d_{i} \Leftrightarrow p_{r}=p_{r 0}-\frac{\Delta_{C}}{\sum_{1}^{I} h_{i} d_{i}}$. Therefore, when $\Delta_{C} \geq 0, p_{r} \leq p_{r 0}$.

Now, we show that $T^{*}$ is the optimal solution to $\mathcal{P}_{2}$ if $\Delta_{C} \geq 0$ and the lowest demand tier does not adopt. Recall that for tiers $i$ that do not adopt, the benefit is $\left(p_{r 0}-p_{r}\right) d_{i}$. For tiers that do adopt, the benefit is $\left(p_{r 0}-p_{r}\right) d_{i}+p_{r} g_{i}-f_{i}-p_{s} g_{i}$. From Lemma 1, $p_{r} g_{i}-f_{i}-p_{s} g_{i} \geq 0$. Therefore, the smallest benefit accrues to the tier with the lowest $d_{i}$ if it does not adopt (from the $\left(p_{r 0}-p_{r}\right) d_{i}$ term; since under $T^{*}$, $\left.p_{r} \leq p_{r 0}\right)$. A household of this tier is best off if $p_{r}$ is as low as possible. Note that the total customer surplus $\Delta_{C}$ is fixed, and how it is distributed among the tiers is controlled by $p_{r}$ and the $f_{i}$ values for adopting tiers. By setting $f_{i}$ values in order to make the $p_{r} g_{i}-f_{i}-p_{s} g_{i}$ values 0 for adopting tiers, we can ensure that $\Delta_{C}$ is constituted of the $\left(p_{r 0}-p_{r}\right) d_{i}$ terms. Tariff $T^{*}$ does exactly this: adopting tiers face fixed costs $f_{i}=\frac{f_{m}}{g_{m}} g_{i}=\left(p_{r}-p_{s}\right) g_{i}$. Therefore, $T^{*}$ ensures that $\Delta_{C}$ is entirely constituted of the $\left(p_{r 0}-p_{r}\right) d_{i}$ terms.

\section{A.2 Modeling purchase as an alternative to PPA}

As an alternative to a PPA model, $S$ could sell solar to customers using an outright sales model. We now describe how our model and analytical results can be extended to accommodate this alternative approach.

First, we require a richer characterization of customers. Define the rooftop area available to a tier $i$ customer as $\rho_{i}$ (measured, for example in $f t^{2}$ ). Based on the amount of available sunlight she receives, unit area of installed rooftop solar panels generates an amount of electricity $\eta_{i}$ per year. Therefore, a tier $i$ customer has an annual generation of $g_{i}=\rho_{i} \eta_{i}$ if she installs solar (of which we continue to assume $e_{i}$ is excess). In this setting, $S$ sets an annualized purchase price $\beta$ per unit area of solar, so that an adopting tier $i$ customer pays $S \$ \beta \rho_{i}$ annually. Similarly, redefine $c_{s}^{z}$ to be measured on the basis of the area of panels that $S$ sells.

The proofs of Propositions 2, 3, and importantly, 5 continue to hold under this model. They follow a similar structure, with some minor modifications First, under this alternative model, a tier $i$ customer now adopts if and only if $\beta \leq \frac{T\left(d_{i}, 0,0\right)-T\left(d_{i}^{\prime}, e_{i}, 1\right)}{\rho_{i}}=t(i)$. Therefore $t(i)$ is now the maximal annualized price of solar (per unit area) that $S$ can charge to induce customer $i$ to adopt. As with the original model, $S$ will set a price $\beta$ equal to $t(i)$ for some $i$. The solar profit given by equation (10) should now be replaced by the equation $\left(t(m)-c_{s}^{z}\right) \sum_{i=1}^{I} s_{i}^{z} h_{i} \rho_{i}=\Delta_{S}$. Similarly, the IC constraints should be replaced by the constraints $\left(t(i)-c_{s}^{z_{i}}\right) \sum_{i=1}^{I} \mathbb{I}_{t(j) \geq t(i)} h_{i} \rho_{i}<\Delta_{S}, \forall t(i) \neq t(m)$. Now, we make the following modifications to our proofs:

- Proposition 2: Instead of ordering tiers by increasing $g_{i}$, we order them by increasing $\rho_{i}$. The $t(i)$ ordering constraints now simplify to $s_{d} \eta_{i}-\frac{\epsilon}{\rho_{i}}<s_{d} \eta_{j}-\frac{\epsilon}{\rho_{j}}, \forall i<j$. The rest of the proof is unaltered.

- Proposition 3: In Part 1, equation (28) is suitably rewritten, and inequalities (29) are rewritten as $t(i)<c_{s}^{z_{i}}+\frac{\Delta_{S}}{\sum_{j=i}^{I} h_{j} \rho_{j}}$. These upper bounds are increasing in $i$ because $c_{s}^{z_{i}}$ is increasing in $i$ and 
$\sum_{j=i}^{I} h_{j} \rho_{j}$ is decreasing in $i$. In Part 2, (30) takes the form $t(i)=r_{m}\left(\frac{d_{i}}{\rho_{i}}\right)+r_{n}\left(\frac{d_{i}-g_{i}}{\rho_{i}}\right)+\frac{\beta}{\rho_{i}}$. The additional terms $\frac{\beta}{\rho_{i}}$ do not depend on $n$ and $m$ and hence do not affect the rest of the proof.

- Proposition 5: Set $t(m)=c_{s}^{z^{*}}+\frac{\Delta_{S}}{\sum_{j=m}^{I} h_{j} \rho_{j}}, t(i)=t(m), \forall i>m$, and $t(i)=c_{s}^{z}$ All,$\forall i<m$. This clearly satisfies the IC constraints and the ordering constraints. For part (b), first, rewrite the statement of Lemma 1 as $p_{r} g_{i}-f_{i}-\beta \rho_{i} \geq 0$ for every adopting tier $i$. For these tiers, the $t(i)$ ordering constraints require that $t(i)=\frac{p_{r} g_{i}-f_{i}}{\rho_{i}} \geq t(m)=\beta$, which proves the lemma. Under $T^{*}$, the decrease in the cash outflow of every non-adopting tier is the same as in the PPA system, while the decrease in the cash outflow of every adopting tier is $p_{r 0} d_{i}-p_{r} d_{i}+p_{r} g_{i}-f_{i}-\beta \rho_{i} \geq\left(p_{r 0}-p_{r}\right) d_{i}$ from Lemma 1 . Since $\Delta_{C}=\sum_{i}^{I} h_{i}\left(p_{r 0}-p_{r}\right) d_{i}>0$, it is immediate that $p_{r}$ is smaller than $p_{r 0}$.

\section{A.3 Preventing customers from exaggerating demand}

(i) Non-Solar to Non-Solar: Non-solar customer $i$ can appear to be non-solar customer $j$ by exaggerating her demand to $\tilde{d}_{i}=d_{j}>d_{i}$. However, doing so increases her bill from $p_{r} d_{i}$ to $p_{r} d_{j}>p_{r} d_{i}$, so she will not do so.

(ii) Non-Solar to Solar: Non-solar customer $i$ can appear to belong to a tier $j$ that adopts solar by installing solar that generates $g_{i}$ and appearing to have a grid usage of $d_{j}^{\prime}=d_{j}-g_{j}+e_{j}$. To do so, she must alter her demand to $\tilde{d}_{i}=\left(d_{j}-g_{j}+e_{j}\right)+g_{i}-e_{i}$. This is undesirable if $\tilde{d}_{i}>d_{i} \Rightarrow\left(d_{j}-g_{j}+e_{j}\right)>$ $\left(d_{i}-g_{i}+e_{i}\right)$. To prevent this from happening, we must ensure that $p_{r} d_{i}<p_{r}\left(\tilde{d}_{i}-g_{i}\right)+f_{j}+p_{s} g_{i}=$ $p_{r}\left(d_{j}-g_{j}+e_{j}-e_{i}\right)+f_{j}+p_{s} g_{i}$. But we have that $p_{r} d_{i}<p_{r}\left(d_{i}-g_{i}\right)+f_{i}+p_{s} g_{i}$. Therefore, it is sufficient for us to choose tariff parameters such that:

$$
p_{r}\left(d_{i}-g_{i}\right)+f_{i}<p_{r}\left(d_{j}-g_{j}+e_{j}-e_{i}\right)+f_{j} .
$$

(iii) Solar to Non-Solar: Solar customer $i$ can appear to be a non-solar customer $j$ by altering her demand $d_{i}$ to $\tilde{d}_{i}=d_{j}$. This is undesirable if $d_{j}>d_{i}$. To prevent this from happening, we must ensure that $p_{r}\left(d_{i}-g_{i}\right)+f_{i}+p_{s} g_{i}<p_{r} d_{j}$. Since tier $i$ adopts, we have that $p_{r}\left(d_{i}-g_{i}\right)+f_{i}+p_{s} g_{i} \leq p_{r} d_{i}$. Since $d_{j}>d_{i}, p_{r} d_{i}<p_{r} d_{j}$; therefore, an adopter $i$ will not spoof a non-adopter $j$.

(iv) Solar to Solar: Solar customer $i$ can appear to be another solar customer $j$ by appearing to have a grid usage of $d_{j}^{\prime}=d_{j}-g_{j}+e_{j}$. To do so, she must alter her demand to $\tilde{d}_{i}=\left(d_{j}-g_{j}+e_{j}\right)+g_{i}-e_{i}$. This is undesirable if $\tilde{d}_{i}>d_{i} \Rightarrow\left(d_{j}-g_{j}+e_{j}\right)>\left(d_{i}-g_{i}+e_{i}\right)$. To prevent this, we must ensure that $p_{r}\left(d_{i}-g_{i}\right)+f_{i}+p_{s} g_{i}<p_{r}\left(\tilde{d}_{i}-g_{i}\right)+f_{j}+p_{s} g_{i}$, which is identical to (31).

Such spoofing behaviors can be eliminated in various ways. For example, constraint (31) could be added to $\mathcal{P}_{2}$ for tiers falling into (ii) and (iv) above, that is, for all tiers $i, j$ such that $d_{j}-g_{j}+e_{j}>d_{i}-g_{i}+e_{i}$ and either $i$ is a non-adopter and $j$ is an adopter, or both $i$ and $j$ are adopters. Whether $\mathcal{P}_{2}$ remains feasible under these constraints depends on the specific parameters under consideration. We show in Section 5 that $\mathcal{P}_{2}$ 's feasibility and CS outcome are unaffected by including these constraints for realistic parameter values. If $R$ does not enforce this constraint in $\mathcal{P}_{2}$, she can use it to check if the solution obtained is exposed to such spoofing behavior. Alternatively, $U$ could assign a tier not just by measuring grid usage, but also by measuring net demand $d_{i}-g_{i}$. Except under pathological parameter values, simply exaggerating demand will not allow a type $i$ customer to mimic a type $j$ customer on both these dimensions.

\section{A.4 Preventing customers from installing inadequate solar}

Let us assume that for every possible $\tilde{g}_{i}<g_{i}, R$ can infer the resulting excess $\tilde{e}_{i}$ based on the customer's usage profile over the day. Such a customer can spoof a tier $j$ customer by choosing capacity $\tilde{g}_{i}$ such that $d_{i}-\tilde{g}_{i}+\tilde{e_{i}}=d_{j}-g_{j}+e_{j}$. For all such pairs of $\tilde{g}_{i}, \tilde{e}_{i}$ values, impose constraint (32), in addition to $f_{m}>0$.

$$
p_{r}\left(d_{i}-g_{i}\right)+f_{i}+p_{s} g_{i}<p_{r}\left(d_{i}-\tilde{g}_{i}\right)+f_{j}+p_{s} \tilde{g}_{i}
$$


Note that we need not consider the possibility of a customer altering both $d_{i}$ and $g_{i}$ to exaggerate her grid usage $d_{i}^{\prime}$ : Decreasing $g_{i}$ by one unit increases her cash outflow by $p_{r}-p_{s}$, while increasing $d_{i}$ by one unit increases her cash outflow by $p_{r}$, which is larger than $p_{r}-p_{s}$.

\section{A.5 Estimation of Parameters for Numerical Study}

Customer parameters: We estimate customer parameters using household micro-data from the U.S. Energy Information Administration's Residential Energy Consumption 2009 Survey (U.S. Energy Information Administration, 2009). This survey contains responses from 112 single-family housing units in the states of Nevada and New Mexico (that appear as a single group in the data). The 2009 data-set pre-dates the solar market uptake, and our resulting estimates are therefore not affected by household adoption decisions. For each housing unit, we estimate the value $g_{i}$ : we take the total area of each house in square feet, as reported in the data set, and divide by the number of stories to obtain an estimate of the total roof area. Then, we assume that each square foot of panel area can generate 9 Watts of electricity when the sun is shining (Solar-Estimate, 2017) to obtain the rated power output of solar panel installations. This estimate is an approximation of installed capacity, because total household area reported in the survey also includes basements and attics, where they are present. Moreover, not all available roof space is typically usable for solar panels. Accordingly, we correct this estimate (as a first approximation) by a single multiplicative factor (24/90) such that installation sizes so obtained are roughly in the $3 \mathrm{~kW}-10 \mathrm{~kW}$ range (Fu et al., 2018). We multiply this installation capacity by the estimated annual number of hours of sun (2190 for Nevada and 2471 hours for New Mexico) to estimate $g_{i}$ (SolarDirect, 2016). We group these households into 4 roughly equally sized buckets $(i=1 \ldots 4)$ based on their generation capacity. Within each bucket $i$, we compute the average energy demanded, $d_{i}$ and the average generation capacity $g_{i}$. We compute bucket size $h_{i}$ as the proportion of these households belonging to generation bucket $i$ (we normalize the total number of households to 1).

Using the U.S. Department of Energy data on hourly residential load in a typical meteorological year for cities in Nevada and New Mexico (US Department of Energy, 2013), we find that residences in Nevada typically consume about $\mu=29 \%$ of their demand between the hours of 11 a.m. and 6 p.m., typical hours for solar reliance. This figure is about $\mu=34 \%$ for New Mexico. Since we do not have this data broken down by household tier, we assume that all houses consume this proportion of their demand when the sun is shining, and use this to estimate $e_{i}$ as $\max \left(0, g_{i}-\mu d_{i}\right)$. The results of this exercise are in Tables 2-3.

Table 2: Estimated parameters for the state of Nevada

\begin{tabular}{|c|c|c|c|c|}
\hline $\begin{array}{c}\text { Generation } \\
\text { Tier }(\mathbf{k W h})\end{array}$ & $\begin{array}{c}\text { Average Generation } \\
g_{i}(\mathbf{k W h})\end{array}$ & $\begin{array}{c}\text { Average Demand } \\
d_{i}(\mathbf{k W h})\end{array}$ & $\begin{array}{c}\text { Average Excess } \\
e_{i}(\mathbf{k W h})\end{array}$ & $\begin{array}{c}\text { \% households } \\
h_{i}\end{array}$ \\
\hline $0-6500$ & 5272 & 8896 & 2636 & $24.11 \%$ \\
\hline $6500-8700$ & 7653 & 10383 & 4577 & $25.00 \%$ \\
\hline $8700-11000$ & 9907 & 13204 & 5995 & $24.11 \%$ \\
\hline$>11000$ & 14483 & 14282 & 10252 & $26.78 \%$ \\
\hline
\end{tabular}

Table 3: Estimated parameters for the state of New Mexico

\begin{tabular}{|c|c|c|c|c|}
\hline $\begin{array}{c}\text { Generation } \\
\text { Tier (kWh) }\end{array}$ & $\begin{array}{c}\text { Average Generation } \\
g_{i}(\mathbf{k W h})\end{array}$ & $\begin{array}{c}\text { Average Demand } \\
d_{i}(\mathbf{k W h})\end{array}$ & $\begin{array}{c}\text { Average Excess } \\
e_{i}(\mathbf{k W h})\end{array}$ & $\begin{array}{c}\text { \% households } \\
h_{i}\end{array}$ \\
\hline $0-7250$ & 5778 & 8810 & 2765 & $21.42 \%$ \\
\hline $7250-9500$ & 8326 & 9808 & 4971 & $24.11 \%$ \\
\hline $9500-12250$ & 10947 & 13303 & 6397 & $26.78 \%$ \\
\hline$>12250$ & 16212 & 14210 & 11352 & $27.68 \%$ \\
\hline
\end{tabular}

\section{Cost parameters:}

$\mathbf{c}_{\mathbf{u}}^{\mathbf{z}_{\mathbf{i}}}$ : For this, we use the low-end levelized cost estimates of various sources of electricity from Lazard (2017), weighted by the energy mix in each state (U.S. Energy Information Administration, 2019a,b). The obtained cost parameters are shown Table 4.

$\mathbf{c}_{\mathbf{s}}^{\mathbf{z}_{\mathbf{i}}}$ : First, we estimate the lifetime production of every Watt of installed capacity. We use a 30 year lifetime (SolarCity, 2017) for solar systems, with output degrading at a rate of $0.5 \%$ per year (Jordan et al., 2010) 
and an average of 1754 hours of sun in the U.S. (SolarDirect, 2016). This gives us an lifetime production of of $39200 \mathrm{kWh}$ of output per kW of installed capacity. Next, we use Sunrun's financial declarations from the third quarter (Q3) of 2019 (Sunrun, 2019). Sunrun deployed $107 \mathrm{MW}$ in Q3, 2019 at a creation cost $\$ 3.28$ per Watt, and $100 \mathrm{MW}$ in Q3, 2018 at a creation cost of $\$ 3.34$ per Watt. Therefore, the total creation cost incurred for deployments in Q3, 2019 is $\$ 350.96$ million and for deployments in Q3, 2019 is $\$ 334$ million. These deployments correspond to a lifetime output of 4194,407,643 kWh in Q3, 2019 and 3920,007,143 kWh in Q3, 2018. Assuming the total creation cost function is linear in the number of $\mathrm{kWh}$ of solar deployed (Fu et al., 2018), we obtain that the total cost function is given by TotalCost $(x)=91714285.71+0.061807468 x$. Now, if outcome $z_{i}$ corresponds to a total solar deployment of $x \mathrm{kWh}$ in a given state (say Nevada), we assume, for simplicity, that this corresponds to a total nationwide deployment of $50 x$ (i.e., that Nevada represents $1 / 50^{t h}$ of the total market). The average $\operatorname{cost} c_{s}^{z_{i}}$ is then given by $c_{s}^{z_{i}}=\frac{91714285.71}{50 x}+\frac{0.061807468}{50}$. This yields $c_{s}^{z_{i}}$ estimates in the range of $\$ 0.0621$ to $\$ 0.0643$ for various $z_{i}$ combinations.

$\mathbf{m}_{\mathbf{u}}^{\mathbf{z}_{\mathbf{i}}}, \mathbf{m}_{\mathbf{s}}$ : We consider two components that contribute to the environmental costs: the monetized value of greenhouse gas (GHG) emissions and the monetized value of other environmental externalities such as the social health costs arising out of NOx, SOx and other particulate matter emissions. We use the GHG emissions of different energy sources published in Intergovernmental Panel on Climate Change (2014) and a social cost of Carbon of $\$ 62.06$ per metric ton of $\mathrm{CO}_{2}$, which we obtain by correcting the 2030 social-cost-of-Carbon estimate of $\$ 502007$ dollars per metric ton of $\mathrm{CO}_{2}$ (Environmental Protection Agency, 2017) for inflation. (Of the years for which estimates are available, 2030 falls closest to the middle of the typical 30 year useable lifetime of a solar panel.) We obtain the monetized value of other externalities directly from National Research Council (2010).

\section{A.6 Reformulation of $\mathcal{P}_{2}$ for Partial Adoption within tiers $\min _{T(\cdot)} \max _{i}\left\{s_{i}^{*}\left(T\left(d_{i}^{\prime}, e_{i}, 1\right)+p_{s} g_{i}-p_{r 0} d_{i}\right), T\left(d_{i}, 0,0\right)-p_{r 0} d_{i}\right\}$ \\ Subject to constraints: \\ $t(i)=\frac{T\left(d_{i}, 0,0\right)-T\left(d_{i}^{\prime}, e_{i}, 1\right)}{g_{i}}, \forall i$ \\ $\left.\sum_{i=1}^{I} h_{i}\left(s_{i}^{*}\left(\pi_{i} T\left(d_{i}^{\prime}, e_{i}, 1\right)+\left(1-\pi_{i}\right)\right) T\left(d_{i}, 0,0\right)\right)+\left(1-s_{i}^{*}\right) T\left(d_{i}, 0,0\right)-c_{u}^{z^{*}}\left(s_{i}^{*}\left(\pi_{i}\left(d_{i}-g_{i}\right)+\left(1-\pi_{i}\right) d_{i}\right)+\left(1-s_{i}^{*}\right) d_{i}\right)\right)-E^{0}=\Delta_{U}$}

$t(i)$ ordering consistent with $o$

$\left(t(m)-c_{s}^{z^{*}}\right) \sum_{i=1}^{I} s_{i}^{*} \pi_{i} h_{i} g_{i}=\Delta_{S}$

$\left(t(i)-c_{s}^{z_{i}}\right) \sum_{j=1}^{I} \mathbb{I}_{o(j)>o(i) \text { in ordering } o} \cdot \pi_{j} h_{j} g_{j}<\Delta_{S}, \forall i \neq m$

\section{A.7 Rate Classes used for New Mexico}

Table 5: Rate Classes - New Mexico

\begin{tabular}{|c|c|c|c|c|c|}
\hline & Class 1 & Class 2 & Class 3 & Class 4 & Class 5 \\
\hline Net demand (kWh) & $0-5921$ & $5921-9309$ & $9309-11555.5$ & $11555.5-13756.5$ & $>13756.5$ \\
\hline Rate & $r_{1}$ & $r_{2}$ & $r_{3}$ & $r_{4}$ & $r_{5}$ \\
\hline
\end{tabular}




\section{A.8 Values of $\pi_{i}$ used in Anable 6: Estimated $\pi$ values}

\begin{tabular}{|c|c|c|}
\hline Generation Tier $(i)$ & Nevada $\pi_{i}$ & New Mexico $\pi_{i}$ \\
\hline $\mathbf{1}$ & $32.72 \%$ & $32.06 \%$ \\
\hline $\mathbf{2}$ & $33.56 \%$ & $34.77 \%$ \\
\hline $\mathbf{3}$ & $30.95 \%$ & $30.42 \%$ \\
\hline $\mathbf{4}$ & $27.10 \%$ & $27.45 \%$ \\
\hline
\end{tabular}

\section{A.9 Modeling Customer Demand Elasticity}

Our extension requires the following conditions on $\tilde{d}_{i}\left(\mu_{i}\right)$ :

- $\tilde{d}_{i}\left(\mu_{i}\right)$ is continuous in $\mu_{i}$.

- $\lim _{\mu_{i} \rightarrow 0} \tilde{d}_{i}\left(\mu_{i}\right)=L_{i}$, for some very large $L_{i}$ : When electricity becomes free, customers consume a very large, but finite amount of electricity.

- $\lim _{\mu_{i} \rightarrow \infty} \tilde{d}_{i}\left(\mu_{i}\right) \mu_{i}=\infty:$ As electricity becomes more expensive, the rate of increase in average price outpaces the rate of decrease in customers' consumption.

To solve the problem with elastic demand, we solve an optimization problem for each compatible adoption outcome and ordering pair, denoted by $(z, o)$. For each such pair, we solve $\mathcal{P}_{3}$, whose objective function is a linear combination of the original objectives of $\mathcal{P}_{1}$ and $\mathcal{P}_{2}$. Let $\theta(z, o)$ be the associated objective value. We choose the tariff corresponding to the outcome $z$ and ordering $o$ that result in the lowest $\theta(z, o)$.

Problem $\mathcal{P}_{3}$ :

$$
\begin{aligned}
\theta(z, o) & =\min _{T(\cdot)}\left[\max _{i}\left(s_{i}^{*}\left(T\left(\tilde{d}_{i}^{\prime}, e_{i}, 1\right)+t(m) g_{i}\right)+\left(1-s_{i}^{*}\right) T\left(\tilde{d}_{i}, 0,0\right)-p_{r 0} d_{i}\right)\right. \\
& \left.-\lambda(\underbrace{c_{u}^{0} E^{0}-c_{u}^{(x)}\left(\sum_{i=m}^{I} h_{i} \tilde{d}_{i}\right)-c_{s}^{z} \Delta_{E}^{z, o}}_{\text {Financial }}+\underbrace{m_{u}^{0} E^{0}-m_{u}^{(x)}\left(\sum_{i=m}^{I} h_{i} \tilde{d}_{i}\right)-m_{s} \Delta_{E}^{z, o}}_{\text {Environmental }})\right] \\
& t(i)=p_{r}-\frac{f_{i}}{g_{i}}, \quad \forall i \\
& \sum_{i=1}^{m-1} h_{i}\left(p_{r}-c_{u}^{(x)}\right) \tilde{d}_{i}+\sum_{i=m}^{I} h_{i}\left(p_{r}\left(\tilde{d}_{i}-g_{i}\right)-c_{u}^{(x)}\left(\tilde{d}_{i}-g_{i}\right)+f_{i}\right)-\sum_{i=1}^{I} h_{i}\left(p_{r 0}-c_{u}^{0}\right) d_{i}=\Delta_{U}
\end{aligned}
$$

$t(i)$ ordering consistent with $o$

$$
\begin{aligned}
& \left(t(m)-c_{s}^{z}\right) \sum_{i=m}^{I} h_{i} g_{i}=\Delta_{S} \\
& \left(t(i)-c_{s}^{z_{i}}\right) \sum_{j=i}^{I} h_{j} g_{j}<\Delta_{S}, \forall t(i) \neq t(m)
\end{aligned}
$$

First, we show that $\mathcal{P}_{3}$ remains feasible for every $z$ and $o$, even when demand is elastic. This is immediate from using schedule $T^{*}$ : the ordering constraints (36) and IC constraints (38) remain valid, as do the constraints (34) linking $f_{i}$ and $t(i)$ and the solar profit constraint (37). Therefore, the feasibility of $\mathcal{P}_{3}$ depends on the feasibility of equation (35). Note that under $T^{*}$, a non-adopter's total cash outflow is $p_{r} \tilde{d}_{i}$. Similarly, an adopter's total cash outflow is $p_{r}\left(\tilde{d}_{i}-g_{i}\right)+p_{s} g_{i}+f_{i}=p_{r}\left(\tilde{d}_{i}-g_{i}\right)+\left(p_{r}-\frac{f_{m}}{g_{m}}\right) g_{i}+g_{i}\left(p_{r}-p_{r}+\frac{f_{m}}{g_{m}}\right)=p_{r} \tilde{\tilde{d}}_{i}$, which again, depends only on $p_{r}$. In both these cases, the average price $\mu_{i}$ of consuming electricity is $p_{r}$.

In $T^{*}$, we have $f_{i}=g_{i}\left(p_{r}-t(m)\right), \forall i>m$. Substituting this in (35) and simplfying, we obtain:

$$
\left(p_{r}-c_{u}^{(x)}\right) \sum_{i=1}^{M} h_{i} \tilde{d}_{i}-c_{u}^{(x)} \sum_{i=m}^{I} h_{i} g_{i}-\Delta_{U}=\left(p_{r 0}-c_{u}^{0}\right) \sum_{i=1}^{I} h_{i} d_{i}+t(m) \sum_{i=m}^{I} h_{i}
$$


Note that the right-hand-side of the equation is positive and independent of $p_{r}$ because $t(m)=c_{s}^{z^{*}}+$ $\Delta_{S} / \Delta_{E}^{(z, o)}>0$. Now, consider the left-hand-side (LHS). Observe that:

- $\lim _{p_{r} \rightarrow 0} L H S=-c_{u}\left(\sum_{i=1}^{M} h_{i} L_{i}\right)\left(\sum_{i=1}^{M} h_{i} L_{i}+\sum_{i=m}^{I} h_{i} g_{i}\right)-\Delta_{U}<0$ for large enough $L_{i}$.

- $\lim _{p_{r} \rightarrow \infty} L H S=\infty$, because the LHS is dominated by the $p_{r} \tilde{d}_{i}$ terms; all other terms are finite.

From continuity, there must exist some intermediate value of $p_{r}$ such that the LHS is equal to the RHS. Therefore, $\mathcal{P}_{3}$ is feasible. It is easy to verify that Proposition 5 continues to hold with demand elasticity, as it relies on the specific tariff implementation $T^{*}$.

\section{References}

Environmental Protection Agency (2017) The Social Cost of Carbon (EPA), URL https:// 19january2017snapshot.epa.gov/climatechange/social-cost-carbon_.html.

Fu R, Feldman DJ, Margolis RM (2018) US Solar Photovoltaic System Cost Benchmark: Q1 2018. Technical report, National Renewable Energy Lab. (NREL), Golden, CO (United States).

Intergovernmental Panel on Climate Change (2014) Technology-specific Cost and Performance Parameters (IPCC), URL https://www.ipcc.ch/pdf/assessment-report/ar5/wg3/ipcc_wg3_ar5_annex-iii. pdf.

Jordan DC, Smith R, Osterwald C, Gelak E, Kurtz SR (2010) Outdoor PV Degradation Comparison. 2010 35th IEEE Photovoltaic Specialists Conference, 002694-002697 (IEEE).

Lazard (2017) Lazard's Levelized Cost of Energy Analysis.

National Research Council (2010) Hidden Costs of Energy: Unpriced Consequences of Energy Production and Use (National Academies Press).

Solar-Estimate (2017) Solar and Wind Calculations: The Basics (Solar-Estimate), URL https: //web.archive.org/web/20170312080146/http://www.solar-estimate.org/?page=solarcalculations.

SolarCity (2017) Solar Panel Lifespan (SolarCity), URL https://web.archive.org/web/20171219181848/ http://www.solarcity.com/residential/solar-energy-faqs/how-long-do-solar-panelslast.

SolarDirect (2016) Solar Electric System Sizing - Determine the Sun Hours Available Per Day (SolarDirect), URL http://www.solardirect.com/pv/systems/gts/gts-sizing-sun-hours.html.

Sunrun (2019) Sunrun Reports Third Quarter 2019 Financial Results (Sunrun), URL https: //investors.sunrun.com/news-events/press-releases/detail/192/sunrun-reports-thirdquarter-2019-financial-results.

US Department of Energy (2013) Commercial and Residential Hourly Load Profiles for all TMY3 Locations in the United States (US Department of Energy), URL http://en.openei.org/doe-opendata/ dataset/commercial-and-residential-hourly-load-profiles-for-all-tmy3-locations-inthe-united-states.

US Energy Information Administration (2009) 2009 RECS Survey Data (EIA), URL https://www.eia. gov/consumption/residential/data/2009/.

US Energy Information Administration (2019a) Nevada State Profile and Energy Estimates (EIA), URL https://www. eia.gov/state/?sid=NV.

US Energy Information Administration (2019b) New Mexico State Profile and Energy Estimates (EIA), URL https://www.eia.gov/state/?sid=NM. 


\section{That's Not Fair: Tariff Structures for Electric Utilities with Rooftop Solar \\ E-Companion}

\section{B.1 Discussion of IC constraints in Problem $\mathcal{P}_{2}$}

This short note establishes that the required IC constraints based on the ordering $o$ match the formulated IC constraints (19). First, it is easy to verify that if all the inequalities in (17) hold strictly, then the required IC constraints (19) are identical to the formulated ones. Suppose instead that the ordering constraints do not all hold strictly, i.e., $\exists a_{1}, a_{2}: o\left(a_{2}\right)>o\left(a_{1}\right)$ and $t\left(a_{1}\right)=t\left(a_{2}\right)$. First, suppose $a_{1} \neq m(o)$ and $a_{2} \neq m(o)$. Then, the required IC constraint must specify that setting $p_{s}=t\left(a_{1}\right)=t\left(a_{2}\right)$ is not in $S$ 's favor. This is identical to the formulated IC constraint in (19) corresponding to $i=a_{1}$. The formulated IC constraint in (19) corresponding to $i=a_{2}$ is dominated by this constraint because $t\left(a_{2}\right)-c_{s}^{z_{a_{2}}}=t\left(a_{1}\right)-c_{s}^{z_{a_{1}}}$, but the summation term corresponding to $i=a_{2}$ is smaller. Therefore, the formulated IC constraint corresponding to $i=a_{2}$ remains valid. Suppose instead that $a_{1}=m(o)$ and $a_{2} \neq m(o)$. Then, since $t\left(a_{1}\right)=t\left(a_{2}\right)$, the formulated constraint (19) corresponding to $i=a_{2}$ is not required (because choosing $p_{s}=t\left(a_{2}\right)=t\left(a_{1}\right)=t(m)$ yields profit $\Delta_{S}$ ), but is still valid because the profit constraint (18) dominates it. Note that it cannot be the case that $a_{1} \neq m(o)$ and $a_{2}=m(o)$, because then we would require that $t\left(a_{1}\right)<t\left(a_{2}\right)$.

\section{B.2 Illustrative example - Solar Competition}

We now illustrate the development of (25)-(26) with an example. Consider a situation with four tiers of customers, with $h_{1}=h_{2}=h_{3}=h_{4}=1$ and $g_{i}=i, \forall i$. Let $\Gamma=2$, and the outcome of $\mathcal{P}_{1}$ determine that tiers 2, 3 and 4 adopt. Now, consider an ordering $t(1)<t(4)<t(2)<t(3)$. Consistent with this ordering, $P(Q)$ is given by: (i) $P(3)=t(3)$; (ii) $P(3+2)=P(5)=t(2)$; (iii) $P(3+2+4)=P(9)=t(4)$; and (iv) $P(3+2+4+1)=P(10)=t(1)$.

Given the outcome of $\mathcal{P}_{1}$, we want the quantity brought to market to be 9 (the market clears at price $t(4))$. Therefore, each of the firms $\gamma=1,2$ must bring a quantity of $9 / 2$ to market. Fixing firm $\gamma=1$ 's quantity $q_{1}=9 / 2$, firm $\gamma=2$ can choose: (i) $q_{2}=1 / 2$, clearing the market at $t(2)$; or (ii) $q_{2}=9 / 2$, clearing the market at $t(4)$; or (iii) $q_{2}=11 / 2$, clearing the market at $t(1)$. For firm $\gamma=2$ 's equilibrium action to be (ii), we require:

$$
\left(t(4)-c_{s}^{z_{\{4,3,2\}}}\right) \frac{9}{2}=\frac{\Delta_{S}}{2} ; \quad\left(t(2)-c_{s}^{z_{\{2,3\}}}\right) \frac{1}{2}<\frac{\Delta_{S}}{2} ; \quad\left(t(1)-c_{s}^{z_{\{1,4,2,3\}}}\right) \frac{11}{2}<\frac{\Delta_{S}}{2}
$$




\section{B.3 Further details to Appendix A.1.1}

We show that $\mathcal{P}_{2}$ is infeasible under orderings $o_{1}$ and $o_{2}$.

System of constraints under $o_{1}$ :

$\frac{1000 r_{d}-700 s_{d}-200 s_{e}+r_{0}-s_{0}}{500}<\frac{2000 r_{d}-1400 s_{d}-400 s_{e}+r_{0}-s_{0}}{1000} \leq \frac{3000 r_{d}-2100 s_{d}-600 s_{e}+r_{0}-s_{0}}{1500}$

$1750000\left(\frac{2000 r_{d}-1400 s_{d}-400 s_{e}+r_{0}-s_{0}}{1000}-c_{s}\right)=\Delta_{S}$

$3750000\left(\frac{1000 r_{d}-700 s_{d}-200 s_{e}+r_{0}-s_{0}}{500}-c_{s}\right)<\Delta_{S}$

$1500000\left(\frac{3000 r_{d}-2100 s_{d}-600 s_{e}+r_{0}-s_{0}}{1500}-c_{s}\right)<\Delta_{S}$

Solving for $r_{0}-s_{0}$ using equation (40), and substituting in (41) and (42), we obtain $5250000\left(5 c_{s}-10 r_{d}+7 s_{d}+2 s_{e}\right)+$ $23 \Delta_{S}<0$ and $700000\left(5 c_{s}-10 r_{d}+7 s_{d}+2 s_{e}\right)+3 \Delta_{S}>0$. Let $\frac{\left(5 c_{s}-10 r_{d}+7 s_{d}\right)}{2}=v$ The above inequalities simplify to $s_{e}+v<\frac{-23}{2(5250000)} \Delta_{S}=-2.19048 \cdot 10^{-6} \Delta_{S}$ and $s_{e}+v>\frac{-3}{2(700000)}=-2.14286 \cdot 10^{-6} \Delta_{S}$, which is not possible, because $\Delta_{S}>0$. Therefore, $\mathcal{P}_{2}$ is infeasible under $o_{1}$.

System of constraints under $o_{2}$ :

$$
\begin{aligned}
& \frac{1000 r_{d}-700 s_{d}-200 s_{e}+r_{0}-s_{0}}{500}<\frac{3000 r_{d}-2100 s_{d}-600 s_{e}+r_{0}-s_{0}}{1500} \leq \frac{2000 r_{d}-1400 s_{d}-400 s_{e}+r_{0}-s_{0}}{1000} \\
& 1750000\left(\frac{3000 r_{d}-2100 s_{d}-600 s_{e}+r_{0}-s_{0}}{1500}-c_{s}\right)=\Delta_{S} \\
& 3750000\left(\frac{1000 r_{d}-700 s_{d}-200 s_{e}+r_{0}-s_{0}}{500}-c_{s}\right)<\Delta_{S} \\
& 250000\left(\frac{2000 r_{d}-1400 s_{d}-400 s_{e}+r_{0}-s_{0}}{1000}-c_{s}\right)<\Delta_{S}
\end{aligned}
$$

Solving for $r_{0}-s_{0}$ using equation (44), and substituting in (43), we obtain:

$$
3 c_{s}-4 r_{d}+\frac{14 s_{d}}{5}+\frac{4 s_{e}}{5}+\frac{3 \Delta_{S}}{1750000}<c_{s}+\frac{\Delta_{S}}{1750000} \leq \frac{3 c_{s}}{2}-r_{d}+\frac{7 s_{d}}{10}+\frac{s_{e}}{5}+\frac{3 \Delta_{S}}{3500000}
$$

Rewriting $c_{s}+\frac{\Delta_{S}}{1750000} \leq \frac{3 c_{s}}{2}-r_{d}+\frac{7 s_{d}}{10}+\frac{s_{e}}{5}+\frac{3 \Delta_{S}}{3500000}$, we obtain $350000\left(5 c_{s}-10 r_{d}+7 s_{d}+2 s_{e}\right)+\Delta_{S} \geq 0$ and rewriting $3 c_{s}-4 r_{d}+\frac{14 s_{d}}{5}+\frac{4 s_{e}}{5}+\frac{3 \Delta_{S}}{1750000}<\frac{3 c_{s}}{2}-r_{d}+\frac{7 s_{d}}{10}+\frac{s_{e}}{5}+\frac{3 \Delta_{S}}{3500000}$, we obtain the opposite, i.e., $350000\left(5 c_{s}-10 r_{d}+7 s_{d}+2 s_{e}\right)+\Delta_{S}<0$.. Therefore, $\mathcal{P}_{2}$ is also infeasible under ordering $o_{2}$.

\section{B.4 Further details to Appendix A.1.4}

Let every individual household in class 1 be worse off by an amount $a_{1}$, and every individual household in class 2 be worse off by an amount $a_{2}$. Because $\Delta_{C}=0$, we have that every household in class 3 is worse off by exactly $-\frac{a_{1} h_{1}+a_{2} h_{2}}{h_{3}}$. Let $\vec{z}^{*}$ specify that class 1 adopts, while classes 2 and 3 do not adopt. Since class 1 is the marginal customer, $r_{2} d_{1}+f=r_{1}\left(d_{1}-g_{1}\right)+f+t(1) g_{1}$ : the class 1 customer is equally worse off whether they adopt solar or not. Accordingly, we can write the following system of equations:

$$
\begin{aligned}
& r_{2} d_{1}+f=p_{r 0} d_{1}+a_{1} \\
& r_{3} d_{2}+f=p_{r 0} d_{2}+a_{2} \\
& r_{4} d_{3}+f=p_{r 0} d_{3}-\frac{a_{1} h_{1}+a_{2} h_{2}}{h_{3}}
\end{aligned}
$$


We solve these equations for $r_{2}, r_{3}$, and $r_{4}$. Next, we use the following profit equation to obtain $r_{1}$ :

$$
\Delta_{S}=h_{1} g_{1}\left(r_{1}+\left(r_{2}-r_{1}\right) \frac{d_{1}}{g_{1}}-c_{s}\right)
$$

Substituting $r_{2}$ from equation (47) into equation (50), we obtain an equation for $r_{1}$. Using these expressions for $r_{1}, r_{2}, r_{3}$, and $r_{4}$, we obtain the following expressions for the $t(i)$ values.

$$
t(1)=\frac{6677}{89000} ; t(2)=\frac{-10 a_{1}+10 a_{2}+181}{1810} ; t(3)=-\frac{89 a_{1}}{68600}-\frac{87 a_{2}}{24500}+\frac{1}{10}
$$

Now, consider the two possible orderings that $R$ could induce.

1. $t(3)<t(2) \leq t(1): t(2) \leq t(1)$ simplifies to the inequality $a_{1} \geq a_{2}+\frac{402363}{89000}$. Therefore, $a$ and $b$ cannot both be made arbitrarily close to 0 .

2. $t(2)<t(3) \leq t(1)$ : Since this ordering requires that $t(2) \leq t(1)$, this ordering also does not allow $R$ to induce a CS-free outcome.

\section{B.5 Results of Numerical Experiments for Scenarios (B) and (C)}

Table 6: Nevada's Experiments for Scenario (B) Rooftop Solar Replaces All Existing Sources, in Proportion

\begin{tabular}{|c|c|c|c|c|c|c|c|}
\hline $\mathcal{P}_{1}$ & \multicolumn{7}{|c|}{$\mathcal{P}_{2}$} \\
\hline \multirow{4}{*}{$\begin{array}{c}\text { Adopting Tiers } \\
\mathbf{1}, \mathbf{2}, \mathbf{3}, \mathbf{4} \\
\text { Objective } \underset{36.71}{\text { Value }}(\$ M M)\end{array}$} & \multicolumn{4}{|c|}{ Sub-Scenario Setting } & \multicolumn{3}{|c|}{$\mathcal{P}_{2}$ Objective Value $(\$)$} \\
\hline & $\begin{array}{c}\Gamma \\
(\$ \mathrm{MM})\end{array}$ & $\left(\$ \stackrel{\Delta_{C}}{\mathrm{MM}}\right)$ & $\left(\$ \stackrel{\Delta_{S}}{\mathrm{MM}}\right)$ & $\left(\$ \stackrel{\Delta_{U}}{\mathrm{MM}}\right)$ & $\begin{array}{l}\text { NV } \\
\text { Tariff }\end{array}$ & $\underset{\text { Tariff }}{\text { Our }}$ & $\underset{\text { Tariff }}{\text { First-Best }}$ \\
\hline & 1 & 0.00 & 0.00 & $\begin{array}{l}-21.85 \\
-22.85\end{array}$ & 10.9 & 0.0 & $\begin{array}{l}0.0 \\
0.0\end{array}$ \\
\hline & 1 & 1.0 & 0.00 & -22.85 & $\begin{array}{l}2.1 \\
9.7\end{array}$ & $\begin{array}{l}0.0 \\
-1.0\end{array}$ & $\begin{array}{l}0.0 \\
-1.2\end{array}$ \\
\hline$\Delta_{W F}(\$ \mathbf{M M})$ & 1 & 1.00 & 1.00 & -23.85 & 0.9 & -0.9 & -1.2 \\
\hline & $\begin{array}{l}3 \\
3\end{array}$ & $\begin{array}{l}0.00 \\
0.00\end{array}$ & $\begin{array}{l}0.00 \\
1.00\end{array}$ & $\begin{array}{l}-21.85 \\
-22.85\end{array}$ & $\begin{array}{l}1.8 \\
1.8\end{array}$ & $\begin{array}{l}0.0 \\
0.0\end{array}$ & $\begin{array}{l}0.0 \\
0.0\end{array}$ \\
\hline$\Delta_{W E_{-}}(\$ \mathbf{M M})$ & 3 & 1.00 & 0.00 & -22.85 & 0.6 & -0 . & -1.2 \\
\hline 58.56 & 3 & 1.00 & 1.00 & -23.85 & 0.6 & -0.9 & -1.2 \\
\hline
\end{tabular}
to Current Mix

Table 7: Nevada's Experiments for Scenario (C) Rooftop Solar Replaces Sources in Descending Order of

\begin{tabular}{|c|c|c|c|c|c|c|c|}
\hline $\mathcal{P}_{1}$ & \multicolumn{7}{|c|}{$\mathcal{P}_{2}$} \\
\hline \multirow{4}{*}{$\begin{array}{c}\text { Adopting Tiers } \\
\mathbf{2}, \mathbf{3}, \mathbf{4} \\
\text { Objective } \underset{92.77}{\text { Value (\$MM) }}\end{array}$} & \multicolumn{4}{|c|}{ Sub-Scenario Setting } & \multicolumn{3}{|c|}{$\mathcal{P}_{2}$ Objective Value $(\$)$} \\
\hline & $\begin{array}{c}\Gamma \\
(\$ \mathrm{MM})\end{array}$ & $\left(\$ \stackrel{\Delta_{C}}{\mathrm{MM}}\right)$ & $\left(\$ \stackrel{\Delta_{S}}{\mathrm{MM}}\right)$ & $\left(\$ \stackrel{\Delta_{U}}{\mathrm{MM}}\right)$ & $\begin{array}{c}\text { NV } \\
\text { Tariff }\end{array}$ & $\begin{array}{c}\text { Our } \\
\text { Tariff }\end{array}$ & $\begin{array}{c}\text { First-Best } \\
\text { Tariff }\end{array}$ \\
\hline & $\begin{array}{l}1 \\
1\end{array}$ & $\begin{array}{l}0.00 \\
0.00\end{array}$ & $\begin{array}{l}0.00 \\
1.00\end{array}$ & $\begin{array}{l}43.45 \\
42.45\end{array}$ & $\begin{array}{c}60.6 \\
2.8\end{array}$ & $\begin{array}{l}0.0 \\
0.0\end{array}$ & \\
\hline & 1 & 1.0 & 0.00 & 42.45 & 59.4 & -0 & -1. \\
\hline$\Delta_{W F}(\$ \mathbf{M M})$ & $\begin{array}{l}1 \\
3\end{array}$ & 1.00 & 1.00 & 41.45 & 1.6 & -0.9 & -1.2 \\
\hline & $\begin{array}{l}3 \\
3\end{array}$ & 0.00 & $\begin{array}{l}0.00 \\
1.00\end{array}$ & $\begin{array}{l}43.45 \\
42.45\end{array}$ & $\begin{array}{l}1.0 \\
1.6\end{array}$ & $\begin{array}{l}0.0 \\
0.0\end{array}$ & $\begin{array}{l}0.0 \\
0.0\end{array}$ \\
\hline$\Delta_{W E}(\$ 9.32$ & $\begin{array}{l}3 \\
3\end{array}$ & $\begin{array}{l}1.00 \\
1.00\end{array}$ & $\begin{array}{l}0.00 \\
1.00\end{array}$ & $\begin{array}{l}42.45 \\
41.45\end{array}$ & $\begin{array}{l}0.4 \\
0.4\end{array}$ & $\begin{array}{l}-0.9 \\
-0.9\end{array}$ & $\begin{array}{l}-1.2 \\
-1.2\end{array}$ \\
\hline
\end{tabular}
Levelized Financial Cost 
Table 8: New Mexico's Experiments for Scenario (B) Rooftop Solar Replaces All Existing Sources, in Proportion to Current Mix

\begin{tabular}{|c|c|c|c|c|c|c|c|}
\hline $\mathcal{P}_{1}$ & \multicolumn{7}{|c|}{$\mathcal{P}_{2}$} \\
\hline \multirow{4}{*}{$\begin{array}{c}\text { Adopting Tiers } \\
\mathbf{1}, \mathbf{2}, \mathbf{3}, 4 \\
\text { Objective Value (\$MM) } \\
66.84\end{array}$} & \multicolumn{4}{|c|}{ Sub-Scenario Setting } & \multicolumn{3}{|c|}{$\mathcal{P}_{2}$ Objective Value $(\$)$} \\
\hline & $\begin{array}{c}\Gamma \\
(\$ \mathrm{MM})\end{array}$ & $\left(\$ \stackrel{\Delta_{C M}}{M}\right)$ & $\left(\$ \stackrel{\Delta_{S}}{M M}\right)$ & $\left(\$ \stackrel{\Delta_{U}}{\mathrm{MM}}\right)$ & $\begin{array}{c}\text { NM } \\
\text { Tariff }\end{array}$ & $\begin{array}{c}\text { Our } \\
\text { Tariff }\end{array}$ & $\begin{array}{c}\text { First-Best } \\
\text { Tariff }\end{array}$ \\
\hline & 1 & 0.00 & 0.00 & -17.29 & 83.0 & 0.0 & \\
\hline & 1 & 0.0 & 1.0 & -18 & 76 & & \\
\hline$\Delta_{W E}(\$ \mathbf{M M})$ & 1 & 1.00 & 1.00 & $\begin{array}{l}-10.29 \\
-19.29\end{array}$ & $\begin{array}{l}81.4 \\
75.1\end{array}$ & $\begin{array}{l}-1.6 \\
-1.6\end{array}$ & $\begin{array}{l}-1.6 \\
-1.6\end{array}$ \\
\hline-17.29 & 3 & 0.00 & 0.00 & -17.29 & 55.4 & 0.0 & 0.0 \\
\hline$\Delta_{W E}(\$ \mathbf{M M})$ & 3 & 1.0 & 0.00 & $\begin{array}{l}-18.29 \\
-18.29\end{array}$ & 38.7 & & $\begin{array}{c}0.0 \\
-1.6\end{array}$ \\
\hline 84.13 & 3 & 1.00 & 1.00 & -19.29 & 37.8 & -1.6 & -1.6 \\
\hline
\end{tabular}

Table 9: New Mexico's Experiments for Scenario (C) Rooftop Solar Replaces Sources in Descending Order of Levelized Financial Cost

\begin{tabular}{|c|c|c|c|c|c|c|c|}
\hline \multirow{4}{*}{$\begin{array}{c}\text { Adopting Tiers } \\
\mathbf{1}, \mathbf{2}, \mathbf{3}, \mathbf{4} \\
\text { Objective Value (\$MM) } \\
150.83\end{array}$} & \multicolumn{7}{|c|}{$\mathcal{P}_{2}$} \\
\hline & \multicolumn{4}{|c|}{ Sub-Scenario Setting } & \multicolumn{3}{|c|}{$\mathcal{P}_{2}$ Objective Value $(\$)$} \\
\hline & $\begin{array}{c}\Gamma \\
(\$ \mathrm{MM})\end{array}$ & $\left(\$ \stackrel{\Delta_{C M}}{\mathbf{M M}}\right)$ & $\left(\$ \frac{\Delta_{S}}{M M}\right)$ & $\left(\$ \stackrel{\Delta_{U}}{\mathrm{MM}}\right)$ & $\begin{array}{l}\text { NM } \\
\text { Tariff }\end{array}$ & $\underset{\text { Tariff }}{\text { Our }}$ & $\underset{\text { Tariff }}{\text { First-Best }}$ \\
\hline & 1 & $\begin{array}{l}0.00 \\
0.00\end{array}$ & $\begin{array}{l}0.00 \\
100\end{array}$ & $\begin{array}{l}-3.67 \\
-4.67\end{array}$ & $\begin{array}{l}83.0 \\
76.8\end{array}$ & $\begin{array}{l}0.0 \\
0.0\end{array}$ & $\begin{array}{l}0.0 \\
0.0\end{array}$ \\
\hline & 1 & $\begin{array}{l}0.00 \\
1.00\end{array}$ & 0.00 & $\begin{array}{l}-4.67 \\
\end{array}$ & 81.4 & -1 & -1.6 \\
\hline $\begin{array}{l}\Delta_{W F}(\$ \mathrm{MM}) \\
-3.67\end{array}$ & 1 & $\begin{array}{l}1.00 \\
0.00\end{array}$ & $\begin{array}{l}1.00 \\
0.00\end{array}$ & $\begin{array}{l}-5.67 \\
-3.67\end{array}$ & $\begin{array}{l}75.1 \\
41.8\end{array}$ & $\begin{array}{c}-1.6 \\
0.0\end{array}$ & $\begin{array}{c}-1.6 \\
0.0\end{array}$ \\
\hline$\Lambda_{U=}(\$ \mathrm{MM})$ & 3 & 0.00 & 1.00 & -4.67 & $\begin{array}{l}28.6 \\
32.9\end{array}$ & 0.0 & -16 \\
\hline 154.51 & 3 & 1.00 & 1.00 & $\begin{array}{l}-5.67 \\
\end{array}$ & 38.4 & -1.6 & -1 \\
\hline
\end{tabular}


Table 10: Nevada - 112-tier Performance for Scenario (B)

\begin{tabular}{|c|c|c|c|c|c|c|c|c|c|c|c|c|c|c|c|c|c|c|c|c|c|}
\hline \multirow[t]{2}{*}{$\Gamma$} & \multicolumn{3}{|c|}{$\begin{array}{c}\mathcal{P}_{1} \text { Objective } \\
(\$ \mathrm{MM})\end{array}$} & \multicolumn{3}{|c|}{$\begin{array}{c}\Delta_{W E} \\
(\$ \mathrm{MM})\end{array}$} & \multicolumn{3}{|c|}{$\begin{array}{c}\Delta_{W F} \\
(\$ \mathrm{MM})\end{array}$} & \multicolumn{12}{|c|}{$\mathcal{P}_{2}$ Objective } \\
\hline & $\begin{array}{l}\text { Tar- } \\
\text { get }\end{array}$ & $\begin{array}{c}\text { NV } \\
\text { Tariff }\end{array}$ & $\begin{array}{c}\text { Our } \\
\text { Tariff }\end{array}$ & $\begin{array}{l}\text { Tar- } \\
\text { get }\end{array}$ & $\begin{array}{c}\text { NV } \\
\text { Tariff }\end{array}$ & $\begin{array}{c}\text { Our } \\
\text { Tariff }\end{array}$ & $\begin{array}{l}\text { Tar- } \\
\text { get }\end{array}$ & $\begin{array}{c}\text { NV } \\
\text { Tariff }\end{array}$ & $\begin{array}{c}\text { Our } \\
\text { Tariff }\end{array}$ & $\begin{array}{l}\text { Tar- } \\
\text { get }\end{array}$ & $\begin{array}{c}\text { NV } \\
\text { Tariff }\end{array}$ & $\begin{array}{l}\text { Our } \\
\text { Tariff }\end{array}$ & $\begin{array}{l}\text { Tar- } \\
\text { get }\end{array}$ & $\begin{array}{c}\text { NV } \\
\text { Tariff }\end{array}$ & $\begin{array}{c}\text { Our } \\
\text { Tariff }\end{array}$ & $\begin{array}{l}\text { Tar- } \\
\text { get }\end{array}$ & $\begin{array}{c}\text { NV } \\
\text { Tariff }\end{array}$ & $\begin{array}{c}\text { Our } \\
\text { Tariff }\end{array}$ & $\begin{array}{l}\text { Tar- } \\
\text { get }\end{array}$ & $\begin{array}{c}\text { NV } \\
\text { Tariff }\end{array}$ & $\begin{array}{c}\text { Our } \\
\text { Tariff }\end{array}$ \\
\hline 1 & & 10.81 & 26.96 & & 18.18 & 43.35 & & -7.37 & -16.39 & 0.00 & 8.22 & 24.62 & 0.00 & $\begin{array}{c}-0.59 \\
\end{array}$ & -0.22 & -21.85 & -15.00 & -40.79 & 0.00 & 39.94 & 0.00 \\
\hline 1 & & 12.68 & 26.96 & & 21.09 & 43.35 & & -8.41 & -16.39 & 0.00 & 6.68 & 24.36 & 1.00 & -0.18 & 0.52 & -22.85 & -14.91 & -41.27 & 0.00 & 3.22 & 0.00 \\
\hline 1 & & 10.81 & 26.96 & & 18.18 & 43.35 & & -7.37 & -16.39 & 1.00 & 9.22 & 25.56 & 0.00 & -0.59 & -0.22 & -22.85 & -16.00 & -41.73 & -1.20 & 38.69 & -0.21 \\
\hline 1 & 36.71 & 12.68 & 26.96 & & 21.09 & 43.35 & 218 & -8.41 & -16.39 & 1.00 & 7.73 & 25.30 & 1.00 & -0.18 & 0.52 & -23.85 & -15.96 & -42.21 & -1.20 & 7.46 & -0.21 \\
\hline 3 & 50.11 & 12.68 & 26.96 & 0.00 & 21.09 & 43.35 & 21.85 & -8.41 & -16.39 & 0.00 & 6.70 & 24.62 & 0.00 & -0.54 & -0.22 & -21.85 & -14.57 & -40.79 & 0.00 & 1.81 & 0.00 \\
\hline 3 & & 12.68 & 26.96 & & 21.09 & 43.35 & & -8.41 & -16.39 & 0.00 & 6.63 & 24.36 & 1.00 & -0.18 & 0.52 & -22.85 & -14.86 & -41.27 & 0.00 & 1.79 & 0.00 \\
\hline 3 & & 12.68 & 26.96 & & 21.09 & 43.35 & & -8.41 & -16.39 & 1.00 & 7.70 & 25.56 & 0.00 & -0.54 & -0.22 & -22.85 & -15.57 & -41.73 & -1.20 & 0.61 & -0.21 \\
\hline 3 & & 12.68 & 26.96 & & 21.09 & 43.35 & & -8.41 & -16.39 & 1.00 & 7.63 & 25.30 & 1.00 & -0.18 & 0.52 & -23.85 & -15.86 & -42.21 & -1.20 & 0.59 & -0.21 \\
\hline
\end{tabular}

Table 11: Nevada - 112-tier Performance for Scenario (C)

\begin{tabular}{|c|c|c|c|c|c|c|c|c|c|c|c|c|c|c|c|c|c|c|c|c|c|}
\hline \multirow[t]{2}{*}{$\Gamma$} & \multicolumn{3}{|c|}{$\begin{array}{c}\mathcal{P}_{1} \text { Objective } \\
(\$ \mathrm{MM})\end{array}$} & \multicolumn{3}{|c|}{$\begin{array}{c}\Delta_{W E} \\
(\$ \mathrm{MM})\end{array}$} & \multicolumn{3}{|c|}{$\begin{array}{c}\Delta_{W F} \\
(\$ \mathrm{MM})\end{array}$} & \multicolumn{12}{|c|}{$\Delta_{U}$} \\
\hline & $\begin{array}{l}\text { Tar- } \\
\text { get }\end{array}$ & $\begin{array}{c}\text { NV } \\
\text { Tariff }\end{array}$ & $\begin{array}{l}\text { Our } \\
\text { Tariff }\end{array}$ & $\begin{array}{l}\text { Tar- } \\
\text { get }\end{array}$ & $\begin{array}{c}\text { NV } \\
\text { Tariff }\end{array}$ & $\begin{array}{l}\text { Our } \\
\text { Tariff }\end{array}$ & $\begin{array}{l}\text { Tar- } \\
\text { get }\end{array}$ & $\begin{array}{c}\text { NV } \\
\text { Tariff }\end{array}$ & $\begin{array}{l}\text { Our } \\
\text { Tariff }\end{array}$ & $\begin{array}{l}\text { Tar- } \\
\text { get }\end{array}$ & $\begin{array}{l}\text { NV } \\
\text { Tariff }\end{array}$ & $\begin{array}{l}\text { Our } \\
\text { Tariff }\end{array}$ & $\begin{array}{l}\text { Tar- } \\
\text { get }\end{array}$ & $\begin{array}{l}\text { NV } \\
\text { Tariff }\end{array}$ & $\begin{array}{l}\text { Our } \\
\text { Tariff }\end{array}$ & $\begin{array}{l}\text { Tar- } \\
\text { get }\end{array}$ & $\begin{array}{l}\text { NV } \\
\text { Tariff }\end{array}$ & $\begin{array}{l}\text { Our } \\
\text { Tariff }\end{array}$ & $\begin{array}{l}\text { Tar- } \\
\text { get }\end{array}$ & $\begin{array}{l}\text { NV } \\
\text { Tariff }\end{array}$ & $\begin{array}{c}\text { Our } \\
\text { Tariff }\end{array}$ \\
\hline 1 & & 41.51 & 44.18 & & 0.83 & 0.39 & & 40.68 & 43.79 & 0.00 & 3.15 & 11.55 & 0.00 & -0.50 & -0.37 & 43.45 & 38.03 & 32.61 & 0.00 & 203.45 & 0.00 \\
\hline 1 & & 42.16 & 44.18 & & 0.84 & 0.39 & & 41.32 & 43.79 & 0.00 & 6.54 & 11.37 & 1.00 & -0.07 & 0.20 & 42.45 & 34.85 & 32.22 & 0.00 & 5.57 & 0.00 \\
\hline 1 & & 41.50 & 44.17 & & 0.83 & 0.39 & & 40.67 & 43.78 & 1.00 & 4.15 & 12.51 & 0.00 & -0.50 & -0.37 & 42.45 & 37.02 & 31.64 & -1.20 & 202.24 & -0.21 \\
\hline 1 & 92.77 & 42.16 & 44.18 & 49.32 & 0.84 & 0.39 & 43.45 & 41.32 & 43.79 & 1.00 & 7.54 & 12.33 & 1.00 & -0.07 & 0.20 & 41.45 & 33.85 & 31.26 & -1.20 & 4.37 & -0.21 \\
\hline 3 & & 42.17 & 44.18 & & 0.84 & 0.39 & & 41.33 & 43.79 & 0.00 & 6.70 & 11.55 & 0.00 & -0.49 & -0.37 & 43.45 & 35.12 & 32.61 & 0.00 & 1.61 & 0.00 \\
\hline 3 & & 42.16 & 44.18 & & 0.84 & 0.39 & & 41.32 & 43.79 & 0.00 & 6.61 & 11.37 & 1.00 & -0.07 & 0.20 & 42.45 & 34.78 & 32.22 & 0.00 & 1.59 & 0.00 \\
\hline 3 & & 42.17 & 44.17 & & 0.84 & 0.39 & & 41.33 & 43.78 & 1.00 & 7.70 & 12.51 & 0.00 & -0.49 & -0.37 & 42.45 & 34.12 & 31.64 & -1.20 & 0.42 & -0.21 \\
\hline 3 & & 42.16 & 44.18 & & 0.84 & 0.39 & & 41.32 & 43.79 & 1.00 & 7.61 & 12.33 & 1.00 & -0.07 & 0.20 & 41.45 & 33.78 & 31.26 & -1.20 & 0.40 & -0.21 \\
\hline
\end{tabular}


Table 12: New Mexico - 112-tier Performance for Scenario (B)

\begin{tabular}{|c|c|c|c|c|c|c|c|c|c|c|c|c|c|c|c|c|c|c|c|c|c|}
\hline \multirow[t]{2}{*}{$\Gamma$} & \multicolumn{3}{|c|}{$\begin{array}{c}\mathcal{P}_{1} \text { Objective } \\
(\$ \mathrm{MM})\end{array}$} & & $\begin{array}{c}\mathcal{P}_{1} \\
\Delta_{W E} \\
(\$ \mathrm{MM}\end{array}$ & & & $\begin{array}{c}\Delta_{W F} \\
(\$ \mathrm{MM})\end{array}$ & & \multicolumn{3}{|c|}{$\begin{array}{c}\Delta_{C} \\
(\$ \mathrm{MM})\end{array}$} & \multicolumn{6}{|c|}{$\mathcal{P}_{2}$} & \multicolumn{3}{|c|}{$\begin{array}{c}\mathcal{P}_{2} \text { Objective } \\
(\$)\end{array}$} \\
\hline & $\begin{array}{l}\text { Tar- } \\
\text { get }\end{array}$ & $\begin{array}{l}\text { NM } \\
\text { Tariff }\end{array}$ & $\begin{array}{l}\text { Our } \\
\text { Tariff }\end{array}$ & $\begin{array}{l}\text { Tar- } \\
\text { get }\end{array}$ & $\begin{array}{c}\text { NM } \\
\text { Tariff }\end{array}$ & $\begin{array}{l}\text { Our } \\
\text { Tariff }\end{array}$ & $\begin{array}{l}\text { Tar- } \\
\text { get }\end{array}$ & $\begin{array}{c}\text { NM } \\
\text { Tariff }\end{array}$ & $\begin{array}{c}\text { Our } \\
\text { Tariff }\end{array}$ & $\begin{array}{l}\text { Tar- } \\
\text { get }\end{array}$ & $\begin{array}{c}\text { NM } \\
\text { Tariff }\end{array}$ & $\begin{array}{l}\text { Our } \\
\text { Tariff }\end{array}$ & $\begin{array}{l}\text { Tar- } \\
\text { get }\end{array}$ & $\begin{array}{c}\text { NM } \\
\text { Tariff }\end{array}$ & $\begin{array}{c}\text { Our } \\
\text { Tariff }\end{array}$ & $\begin{array}{l}\text { Tar- } \\
\text { get }\end{array}$ & $\begin{array}{c}\text { NM } \\
\text { Tariff }\end{array}$ & $\begin{array}{l}\text { Our } \\
\text { Tariff }\end{array}$ & $\begin{array}{l}\text { Tar- } \\
\text { get }\end{array}$ & $\begin{array}{c}\text { NM } \\
\text { Tariff }\end{array}$ & $\begin{array}{c}\text { Our } \\
\text { Tariff }\end{array}$ \\
\hline 1 & & $\begin{array}{l}19.32 \\
\end{array}$ & 60.14 & & 24.84 & 75.78 & & -5.52 & -15.64 & 0.00 & 15.69 & 211.33 & 0.00 & -0.41 & -0.06 & \begin{tabular}{|l|}
-17.29 \\
\end{tabular} & -20.80 & -226.91 & 0.00 & 263.92 & 0.00 \\
\hline 1 & & 19.32 & 60.14 & & 24.84 & 75.78 & & -5.52 & -15.64 & 0.00 & 15.24 & 208.13 & 1.00 & -0.12 & 0.84 & -18.29 & -20.64 & -224.61 & 0.00 & 253.46 & 0.00 \\
\hline 1 & & 19.32 & 60.14 & & 24.84 & 75.78 & & -5.52 & -15.64 & 1.00 & 16.69 & 212.33 & 0.00 & -0.41 & -0.06 & -18.29 & -21.80 & -227.91 & -1.60 & 262.28 & -1.63 \\
\hline 1 & 66.84 & 19.32 & 60.14 & & 24.84 & 75.78 & & -5.52 & -15.64 & 1.00 & 16.24 & 209.13 & 1.00 & -0.12 & 0.84 & -19.29 & -21.64 & -225.61 & -1.60 & 251.83 & -1.63 \\
\hline 3 & 66.84 & 23.00 & 60.14 & 84.13 & 29.44 & 75.78 & -17.29 & -6.44 & -15.64 & 0.00 & 27.41 & 211.33 & 0.00 & -0.38 & -0.06 & -17.29 & -33.47 & -226.91 & 0.00 & 217.40 & 0.00 \\
\hline 3 & & 23.01 & 60.14 & & 29.44 & 75.78 & & -6.43 & -15.64 & 0.00 & 26.94 & 208.13 & 1.00 & -0.03 & 0.84 & -18.29 & -33.34 & -224.61 & 0.00 & 205.17 & 0.00 \\
\hline 3 & & 27.10 & 60.14 & & 34.56 & 75.78 & & -7.46 & -15.64 & 1.00 & 15.66 & 212.33 & 0.00 & -0.35 & -0.06 & -18.29 & -22.77 & -227.91 & -1.60 & 223.77 & -1.63 \\
\hline 3 & & 25.71 & 60.14 & & 32.81 & 75.78 & & -7.10 & -15.64 & 1.00 & 19.24 & 209.13 & 1.00 & 0.03 & 0.84 & -19.29 & -26.37 & -225.61 & -1.60 & 215.61 & -1.63 \\
\hline
\end{tabular}

Table 13: New Mexico - 112-tier Performance for Scenario (C)

\begin{tabular}{|c|c|c|c|c|c|c|c|c|c|c|c|c|c|c|c|c|c|c|c|c|c|}
\hline \multirow[t]{2}{*}{$\Gamma$} & \multicolumn{3}{|c|}{$\begin{array}{c}\mathcal{P}_{1} \text { Objective } \\
(\$ \mathrm{MM})\end{array}$} & \multicolumn{3}{|c|}{$\begin{array}{c}\mathcal{P}_{1} \\
\Delta_{W E} \\
(\$ \mathrm{MM})\end{array}$} & \multicolumn{3}{|c|}{$\begin{array}{c}\Delta_{W F} \\
(\$ \mathrm{MM})\end{array}$} & \multicolumn{3}{|c|}{$\begin{array}{c}\Delta_{C} \\
(\$ \mathrm{MM})\end{array}$} & \multicolumn{6}{|c|}{$\mathcal{P}_{2}$} & \multicolumn{3}{|c|}{$\begin{array}{c}\mathcal{P}_{2} \text { Objective } \\
(\$)\end{array}$} \\
\hline & $\begin{array}{l}\text { Tar- } \\
\text { get }\end{array}$ & $\begin{array}{c}\text { NM } \\
\text { Tariff }\end{array}$ & $\begin{array}{l}\text { Our } \\
\text { Tariff }\end{array}$ & $\begin{array}{l}\text { Tar- } \\
\text { get }\end{array}$ & $\begin{array}{l}\text { NM } \\
\text { Tariff }\end{array}$ & $\begin{array}{l}\text { Our } \\
\text { Tariff }\end{array}$ & $\begin{array}{l}\text { Tar- } \\
\text { get }\end{array}$ & $\begin{array}{l}\text { NM } \\
\text { Tariff }\end{array}$ & $\begin{array}{l}\text { Our } \\
\text { Tariff }\end{array}$ & $\begin{array}{l}\text { Tar- } \\
\text { get }\end{array}$ & $\begin{array}{l}\text { NM } \\
\text { Tariff }\end{array}$ & $\begin{array}{l}\text { Our } \\
\text { Tariff }\end{array}$ & $\begin{array}{l}\text { Tar- } \\
\text { get }\end{array}$ & $\begin{array}{l}\text { NM } \\
\text { Tariff }\end{array}$ & $\begin{array}{l}\text { Our } \\
\text { Tariff }\end{array}$ & $\begin{array}{l}\text { Tar- } \\
\text { get }\end{array}$ & $\begin{array}{l}\text { NM } \\
\text { Tariff }\end{array}$ & $\begin{array}{l}\text { Our } \\
\text { Tariff }\end{array}$ & $\begin{array}{l}\text { Tar- } \\
\text { get }\end{array}$ & $\begin{array}{c}\text { NM } \\
\text { Tariff }\end{array}$ & $\begin{array}{c}\text { Our } \\
\text { Tariff }\end{array}$ \\
\hline 1 & & 42.40 & 135.56 & & 43.56 & 138.88 & & -1.16 & -3.32 & 0.00 & 15.69 & 211.33 & 0.00 & -0.41 & -0.06 & -3.67 & -16.44 & -214.59 & 0.00 & 263.92 & 0.00 \\
\hline 1 & & 42.40 & 135.56 & & 43.56 & 138.88 & & -1.16 & -3.32 & 0.00 & 15.24 & 208.13 & 1.00 & -0.12 & 0.84 & -4.67 & -16.28 & -212.29 & 0.00 & 253.46 & 0.00 \\
\hline 1 & & 42.40 & 135.56 & & 43.56 & 138.88 & & -1.16 & -3.32 & 1.00 & 16.69 & 212.33 & 0.00 & -0.41 & -0.06 & -4.67 & -17.44 & -215.59 & -1.60 & 262.28 & -1.63 \\
\hline 1 & 150.8 & 42.40 & 135.56 & 54.51 & 43.56 & 138.88 & 367 & -1.16 & -3.32 & 1.00 & 16.24 & 209.13 & 1.00 & -0.12 & 0.84 & -5.67 & -17.28 & -213.29 & -1.60 & 251.83 & -1.63 \\
\hline 3 & 150.84 & 57.97 & 135.56 & 4.51 & 59.48 & 138.88 & $.6 r$ & -1.51 & -3.32 & 0.00 & 15.32 & 211.33 & 0.00 & -0.35 & -0.06 & -3.67 & -16.48 & -214.59 & 0.00 & 224.84 & 0.00 \\
\hline 3 & & 50.82 & 135.56 & & 52.17 & 138.88 & & -1.35 & -3.32 & 0.00 & 26.94 & 208.13 & 1.00 & -0.03 & 0.84 & -4.67 & -28.26 & -212.29 & 0.00 & 205.17 & 0.00 \\
\hline 3 & & 60.18 & 135.56 & & 61.76 & 138.88 & & -1.58 & -3.32 & 1.00 & 10.94 & 212.33 & 0.00 & -0.35 & -0.06 & -4.67 & -12.17 & -215.59 & -1.60 & 228.04 & -1.63 \\
\hline 3 & & 50.82 & 135.56 & & 52.17 & 138.88 & & -1.35 & -3.32 & 1.00 & 27.94 & 209.13 & 1.00 & -0.03 & 0.84 & -5.67 & -29.26 & -213.29 & -1.60 & 203.53 & -1.63 \\
\hline
\end{tabular}

